\title{
SRAM Cell Leakage Control Techniques for Ultra Low Power Application: A Survey
}

\author{
Pavankumar Bikki, Pitchai Karuppanan \\ Department of Electronics and Communication, Motilal Nehru National Institute of Technology, Allahabad, India \\ Email: bikkipavan@gmail.com
}

How to cite this paper: Bikki, $\mathrm{P}$. and $\mathrm{Ka}$ ruppanan, P. (2017) SRAM Cell Leakage Control Techniques for Ultra Low Power Application: A Survey. Circuits and Systems, 8, 23-52.

https://doi.org/10.4236/cs.2017.82003

Received: January 16, 2017

Accepted: February 25, 2017

Published: February 28, 2017

Copyright $\odot 2017$ by authors and Scientific Research Publishing Inc. This work is licensed under the Creative Commons Attribution International License (CC BY 4.0).

http://creativecommons.org/licenses/by/4.0/ (c) (i) Open Access

\begin{abstract}
Low power supply operation with leakage power reduction is the prime concern in modern nano-scale CMOS memory devices. In the present scenario, low leakage memory architecture becomes more challenging, as it has $30 \%$ of the total chip power consumption. Since, the SRAM cell is low in density and most of memory processing data remain stable during the data holding operation, the stored memory data are more affected by the leakage phenomena in the circuit while the device parameters are scaled down. In this survey, origins of leakage currents in a short-channel device and various leakage control techniques for ultra-low power SRAM design are discussed. A classification of these approaches made based on their key design and functions, such as biasing technique, power gating and multi-threshold techniques. Based on our survey, we summarize the merits and demerits and challenges of these techniques. This comprehensive study will be helpful to extend the further research for future implementations.
\end{abstract}

\section{Keywords}

Body Biasing, Gate Leakage, Junction Leakage, Power Gating, Multi-Threshold, SRAM Cell, Sub-Threshold Leakage

\section{Introduction}

To accomplish high-density chip, ultra-low power dissipation, and high performance, complementary metal oxide semiconductor (CMOS) devices have been scaled since last 30 years. As a result, the propagation delay time has been reduced by $30 \%$ per technology leading to the microprocessor performance being doubled every two years. Scaled technology has reduced the supply voltage to obtain low power consumption [1] [2] [3] [4]. Additionally, a scaled technology also has reduced device parameters such as threshold voltage, channel length and gate oxide thickness. However, the scaled technology has two drawbacks. 
First, a low- $V_{T H}$ device has an exponential increase in sub-threshold leakage. Sub-threshold leakage rises by ten times for every 0.1-volt decrease of the threshold voltage [5] [6] [7]. The second problem is the reduction of worst-case performance due to threshold variation at lower supplies [8] [9] [10]. As technology scales down, leakage current in a sub-micron region becomes more significant and is comparable with the dynamic power dissipation. Figure 1(a) shows the full chip leakage power dissipation based on the international technology roadmap for semiconductor (ITRS) [11] [12]. Various components affecting the subthreshold leakage, gate leakage, and junction leakage are depicted in Figure 1 (b). However, finding and modelling of the several leakage mechanisms are essential for evaluation and minimization of leakage current for low power application [13] [14].

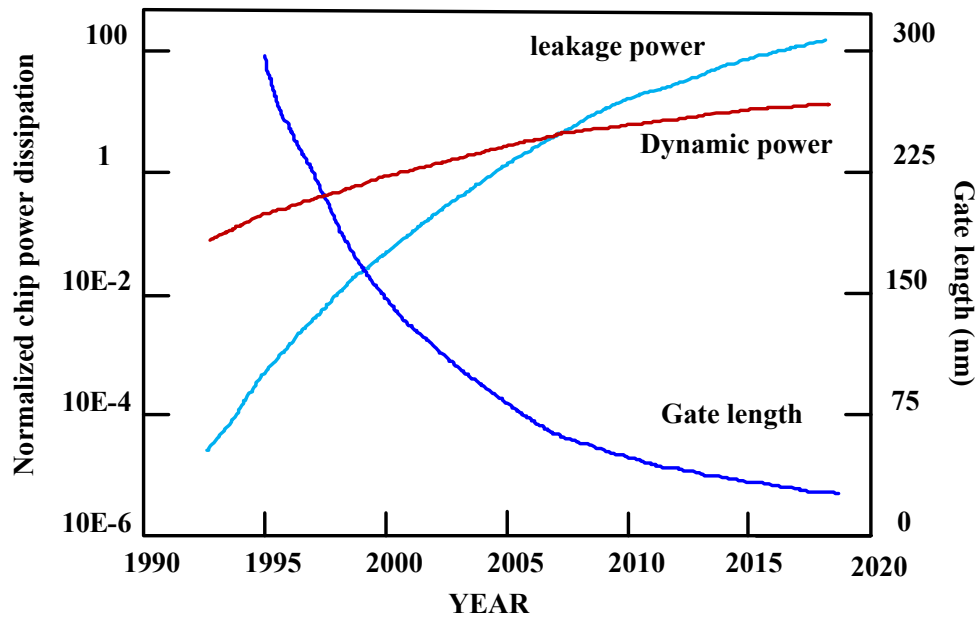

(a)

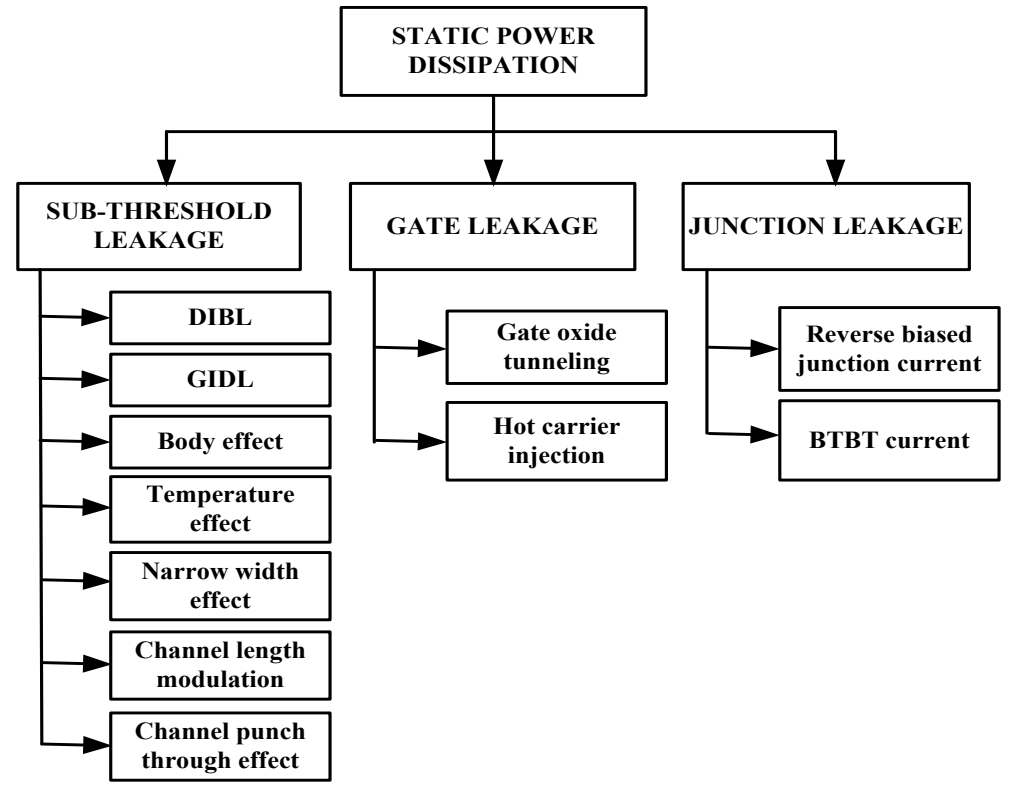

(b)

Figure 1. (a) Full chip power dissipation based on ITRS. (b) Leakage currents components. 
Generally, device non-conducting current $\left(I_{\mathrm{OFF}}\right)$ depends on the supply voltage, threshold voltage, length of the channel, surface/channel doping profile, drain/source junction depth and gate oxide thickness [15]. For long channel devices $I_{\mathrm{OFF}}$ mainly originates from the drain-source reverse bias junctions. Short-channel device needs low power supply in order to reduce power dissipation [16] [17]. Hence, the reduced threshold voltage causes exponential increase in $I_{\mathrm{OFF}}$ current due to the weak-inversion region [18] [19].

A conventional 6T SRAM cell consists of two inverters connected back to back and two access NMOS transistors as shown in Figure 2(a). The SRAM cell leakage versus technology scaling is shown in Figure 2(b). It shows that the

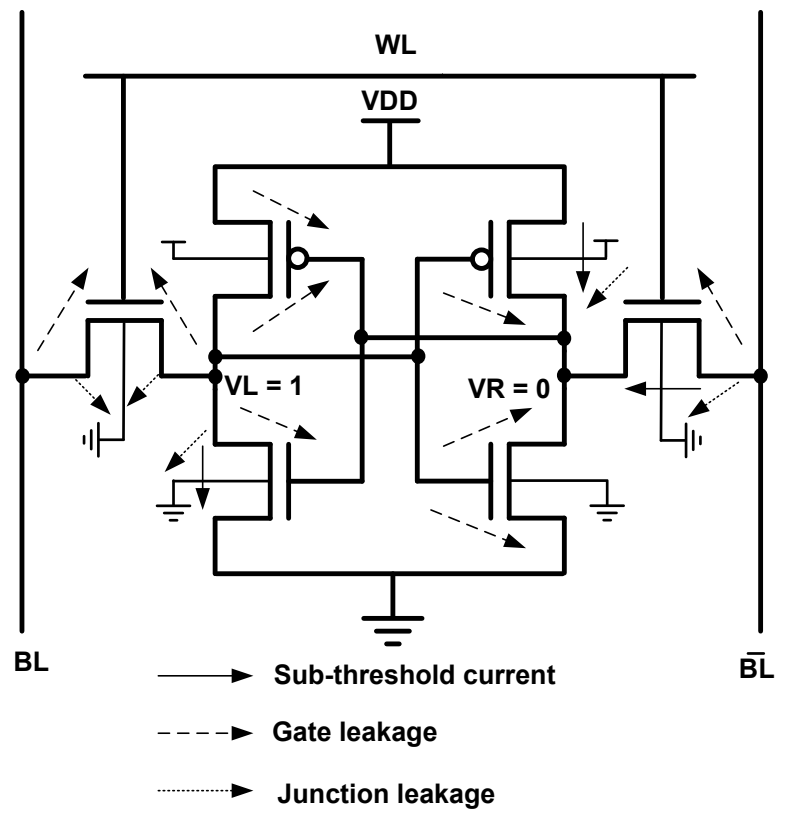

(a)

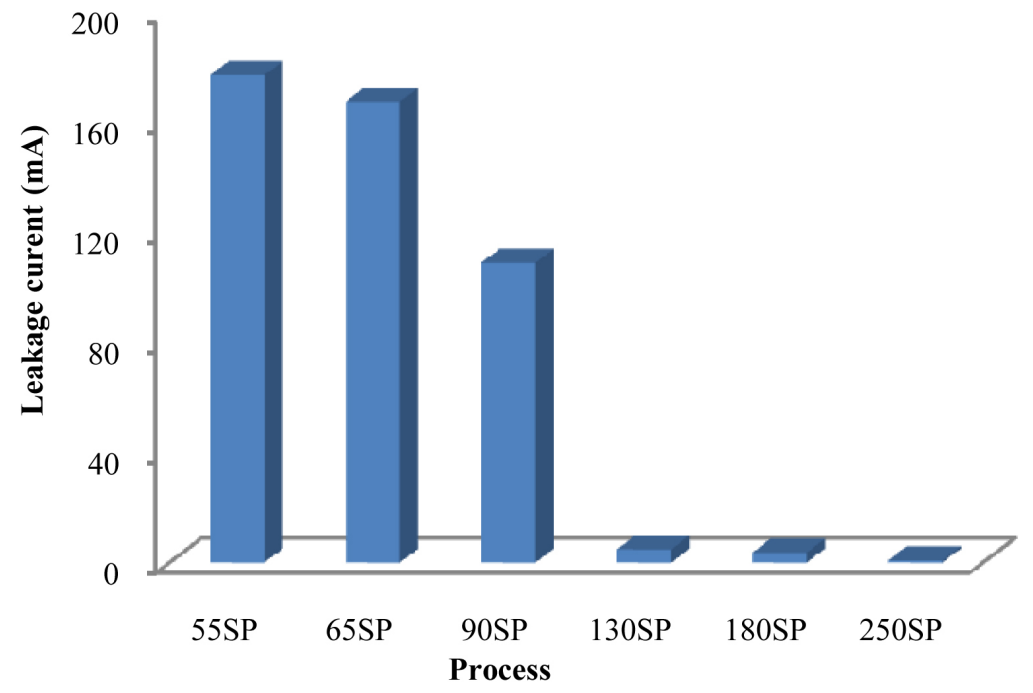

(b)

Figure 2. (a) Leakage phenomena in basic SRAM cell (b) SRAM Leakage current versus technology node [24]. 
leakage current exponential increased with technology scaling below $90 \mathrm{~nm}$. Sub-threshold leakage arises whenever the transistor gate voltage is zero and the drain-source voltage is non-zero. Hence, leakage current can arise within the bit cell or on the bit line access paths [20] [21]. The transistor leakage in SRAM cell essentially depends on 1) the data value stored in the cell, 2) the logic data level of the word line and 3) the type of operation being performed. Bit line leakage current is a very small amount as compared to total cell leakage. However, the bit line leakage is a very important factor, as the bit line leakage can affect the constancy of the memory stored in the cell [22] [23]. The total leakage current is given by

$$
\left(I_{\text {total-leak }}=I_{\text {sub_th }}+I_{\text {gate }}+I_{\text {junction }}\right)
$$

In order to bring the classification of leakage minimization approaches, we analyzed based on their fundamental design and mechanism. A brief summary of different leakage control schemes with their merits and demerits along with the limitations by using these schemes is presented. This paper will be helpful for researches to work towards emerging power-efficient memory designs for ultralow power applications. The rest of the paper is organized as follows. Section 2 presents the origin of leakage current in a short-channel device. Various biasing techniques for leakage control SRAM are discussed in Section 3. Emerging power gating techniques for low power SRAM designs are presented in Section 4. Asymmetrical SRAM designs with multi-threshold transistor are described and comparisons of various low power techniques are tabulated in Section 5. Finally, the survey paper concludes in Section 6.

\section{Leakage Currents}

Basic leakage currents in a MOS transistor are as shown in Figure 3. Three types of leakage currents are presented when the device channel is in a non-conducting state, which are sub-threshold leakage current $\left(I_{\text {Sub_th }}\right)$, gate-induced drain leakage $\left(I_{\mathrm{GIDL}}\right)$ and punch-through leakage $\left(I_{\text {Punch }}\right)$ [25]. Two other leakage currents that are independent of the conduction of the device are gate tunneling current $\left(I_{\text {tunnel }}\right)$ and pn junction reverse bias leakage $\left(I_{\text {junction }}\right)$ due to a band to band tunneling effect [26] [27].

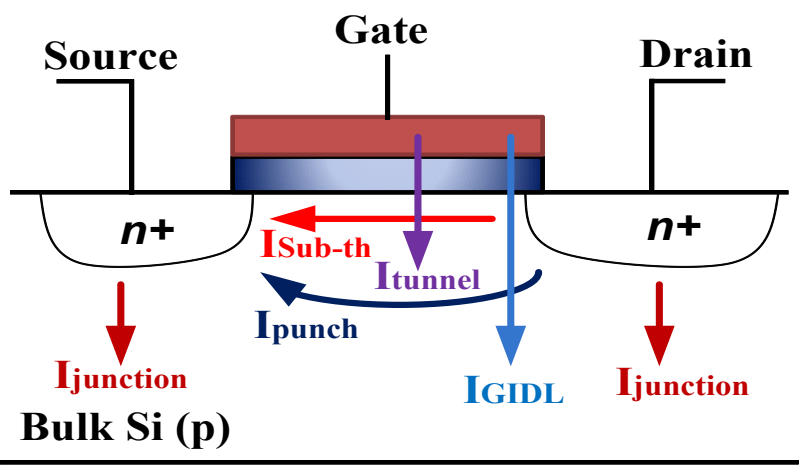

Figure 3. Leakage currents in a MOSFET. 


\subsection{Sub-Threshold or Weak Inversion Current}

Sub-threshold or weak inversion current is present between the source and the drain terminals of the MOSFET transistor when the gate voltage is less than the threshold voltage of the device $\left(V_{G S}<V_{T H}\right)$. Weak inversion region has small minority carrier concentration and it varies along with the length of the channel. The drift current dominates in the strong inversion region and the diffusion current dominates in weak inversion region [28] [29] [30]. Let us assume that the source of the NMOS is zero $\left(V_{G}<V_{T H}\right)$ and the drain to source voltage is greater than $1 \mathrm{~V}$. In this case, weak inversion current at $V_{D S}$ falls completely due to the existence of reverse-biased subtract-drain pn junction [10] [31]. The NMOS transistor Gate-source voltage versus drain current has presented in Figure 4, which represents the sub-threshold and junction currents when the threshold voltage is $0.6 \mathrm{~V}$. Drain current for NMOS transistor function in weak-in- version region is given by

$$
I_{D(\text { weak inversion })}=I_{\text {on }} \cdot e^{\left(V_{G S} / V_{T}\right)}
$$

where $\eta$ is sub-threshold slope coefficient; $V_{T}$ is the thermal voltage equal to $q / K T$; and $I_{\text {on }}$ is $\mu_{o} C_{o x}(W / L) V_{t}^{2} e^{1.8}$.

\subsection{Gate-Induced Drain Leakage}

Gate-induced drain leakage (GIDL) occurs due to band to band tunneling at gate-drain overlap region under the strong electric field. Electrical field increases with the decreasing the depletion layer at the surface. The GIDL is more in case of single-diffused drain as compared to double-diffused drain. At low subtract voltage the minority carrier accumulated into drain depletion region under the gate region that forms the path for the GIDL current [32] [33]. Further the GIDL current increases exponential with thinner gate oxide thickness, low- $V_{T H}$ and the higher potential difference between gate and drain [34] [35]. A simple mathematical analysis is presented for the effect of gate work function in the electric

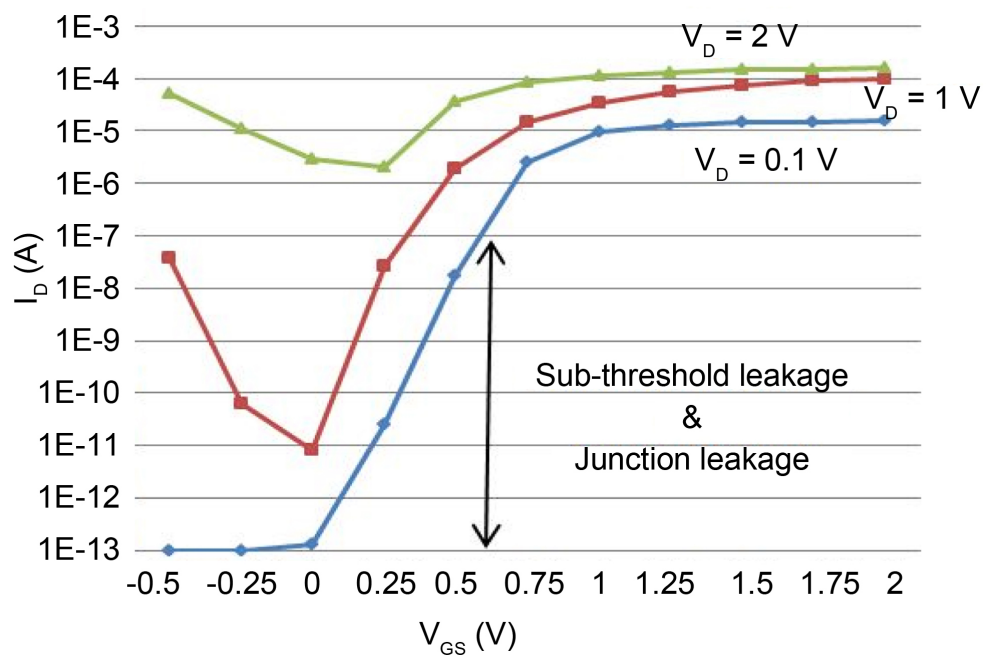

Figure 4. Gate-source voltage vs. drain current. 
field at the gate-drain overlap in Equation (3).

$$
E_{\text {Total }}^{2}=\frac{\frac{V_{D G}}{T_{O X}}\left(1-\frac{V_{F B}-\psi_{S}}{V_{D G}}\right)^{2}+\frac{V_{D G}^{2}}{\gamma h}}{T_{O X}}
$$

Based on the tunneling theory, the $I_{G I D L}$ current can be written as

$$
I_{G I D L}=A E_{G I D L}^{2} \exp \left(\frac{-B}{E_{G I D L}}\right)
$$

where $\psi_{S}$ is the potential drop across the silicon for BTBT; $h$ is the parameter interrelated to junction depth, $E_{G I D L}$ the electric field accountable for GIDL current; $A$ and $B$ are constants that aid in tunneling [36] [37].

\subsection{Punch-Through Current}

Punch-through current occurs in small-geometry MOS transistors due to the nearness of the source and drain depletion regions as there junctions spread into the short-channel (i.e., when $x_{d S}+x_{d D}=L$ ). Since the short-channel doping concentration remains constant as a result the boundaries between the depletion regions are reduced [38] [39]. In submicron technology, the surface region was highly doped as compared to the substrate and the depletion region extended towards the substrate which rises the punch-through current below the surface [40] [41]. Punch-through current can be reduced with higher substrate doping, small oxides, modest junctions and preferably with long channels.

In short-channel devices, the potential barrier is governed by both the drain-to-source voltage $V_{D S}$ and the gate-to-source voltage $V_{G S}$. When the drain voltage is increased, it decreases the potential barrier in the short channel, leading to drain-induced barrier lowering (DIBL). Carriers are injected into the channel surface from the source region independent of the gate voltage [42]. The drain and source junction widths are expressed as

$$
\begin{gathered}
x_{d D}=\sqrt{\left[\frac{2 \varepsilon_{S i}}{q N_{A}}\right]\left(V_{D S}+\varnothing_{s i}+V_{S B}\right)} \\
x_{d s}=\sqrt{\left[\frac{2 \varepsilon_{S i}}{q N_{A}}\right]\left(\varnothing_{s i}+V_{D B}\right)}
\end{gathered}
$$

The sub-threshold surface diffusion current $\left(I_{\text {Sdif }}\right)$ for short channel at its saturation level $\left(\left|V_{d s}\right|>\frac{4 k T}{q} \approx 0.1 V\right)$ can be expressed as [43].

$$
\begin{gathered}
I_{\text {Sdif }} \propto D n_{i}^{2} e^{\left(q \Delta \emptyset_{s} / k T\right)} / L_{\text {eff }} \\
\Delta \varnothing_{s}=\Delta \varnothing_{s o}\left(V_{g s}, V_{b s}\right)+m\left|V_{d s}\right|
\end{gathered}
$$

where $D$ is the surface diffusion constant of minority carriers; $n_{i}$ is the intrinsic carrier concentration; $\Delta \varnothing_{s o}$ is the surface-band-bending (a function of $\left.V_{g s}, V_{b s}\right)$ and $m$ is a dimensionless constant.

Two other leakage currents that are independent of the conduction of the de- 
vice are gate tunneling current and pn junction reverse bias leakage due to a band to band tunneling effect $\left(\mathrm{I}_{\text {Втвт }}\right)$ [26] [27].

\subsection{Gate Tunneling Current}

Gate tunneling current occurs due to the high electric field formed across the small gate oxide layer. Gate tunneling current depends on the device structure and biasing conditions. At high electric field, tunneling of electrons take place from gate to bulk and also from bulk to gate region through the gate oxide layer (i.e the quantum-mechanical wave function of a charged carrier [44]). Highly charged electrons can easily enter into or through the oxide layer due to small width of potential barrier. It increases the gate current [45] [46]. On the other hand, if the gate voltage is less than zero $(V g<0)$ the charged electrons in $n+$ poly-silicon can easily tunnel into or through the gate oxide and form a gate current. Gate tunneling current depends on the device structure and biasing conditions. Gate tunneling current in a scaled device contains a gate-to-channel current $\left(I_{g c}\right)$ and edge direct tunneling currents $\left(I_{g s o}\right)$ and $\left(I_{g d o}\right)$ [47] [48].

$$
I_{g}=I_{g c}+I_{g s o}+I_{g d o}
$$

Gate tunneling current is divided into mainly two types, Flowler-Nord-heim (FN) tunneling and direct tunneling. In FN tunneling mechanism, electrons tunnel straight into the conduction band through the forbidden band gap of the oxide layer [49] [50]. The direct tunneling current form between the sourcedrain extension and the gate overlap. Direct tunneling occurs mainly due to the electrons and holes tunneling, the electron tunnel from the conduction band and the valence band while the holes tunnel from valence band. It is more sensitive to the gate oxide thickness [51]. The $F N$ current expression represents the tunneling through the triangular potential barrier and is valid for $V_{o x}>\varnothing_{o x}$, where $V_{o x}$ denotes the voltage drop across the oxide. The current density of $F N$ tunneling is expressed as

$$
J_{F N}=\frac{q^{3} E_{o x}^{2}}{16 \pi^{2} h \varnothing_{o x}} \exp \left(-\frac{4 \sqrt{2 m} \varnothing_{o x}^{3 / 2}}{3 h q E_{o x}}\right)
$$

where $E_{o x}$ is electric field across the gate oxide; $\varnothing_{o x}$ is the potential barrier height for electrons and $m$ is the mass of an electron in the conduction band [52] [53].

\subsection{Junction Leakage}

Generally, body-to-drain and body-to-source junction are in reverse bias, which produces a pn junction reverse bias leakage current. In small-geometry devices, highly doped $p$ and $n$ regions cause a band-to-band tunneling (BTBT) leakage. The pn junction reverse bias leakage current primarily originates from minority carrier diffusion and drift current near the depletion region. Secondly, in reverse biased pn junction, the depletion region generates electron-hole pair. The reverse bias pn junction leakage current is mainly dependent on the doping concentration and depletion junction area [54] [55]. The BTBT current density is 
given by

$$
J_{B-B}=A \frac{E V_{\text {app }}}{E_{g}^{1 / 2}} \exp \left(-B \frac{E_{g}^{3 / 2}}{E}\right)
$$

where $m$ is the mass of an electron; $E_{g}$ is the energy-band gap; $V_{\text {app }}$ is the applied reverse bias; $E$ is the electric field at the junction; $q$ is the electronic charge; and $h$ is $1 / 2 \pi$ times Planck's constant.

\section{Biasing Techniques}

Generally the body terminal of the transistors is connected to the supply voltage ( $V_{D D}$ in the case of PMOS and GND in the case of NMOS) in order to control a threshold voltage. In the case of reverse body bias (RBB), the body voltage of PMOS is greater than the $V_{D D}$ and the body voltage of NMOS is less than $V_{G N D}$. This results in an increase in depletion layer width. The higher gate voltage is required to create an inversion layer by increasing the threshold voltage [56] [57] [58]. Similarly, in forward body bias (FBB) the body voltage of PMOS is less than the $V_{D D}$ and the body voltage of NMOS is greater than $V_{G N D}$. As a result, the depletion layer width is reduced. The smaller gate voltage creates the inversion layer thereby decreasing threshold voltage. Consequently FBB has fast transition [59] [60]. Analysis of NMOS body bias versus threshold voltage and leakage current is as shown in Figure 5(a) and Figure 5(b). PMOS body bias versus threshold voltage and leakage current is as shown in Figure 5(c) and Figure 5(d). These analysis shows that the FBB has lower- $V_{T H}$ it increase the leakage current exponential and RBB has higher- $V_{T H}$ it reduce the leakage current. Various biasing ideas to design high- $V_{T H}$ PMOS and NMOS transistors given in Table 1 and the arrows represent the sub-threshold current. In bulk MOSFETs, the threshold voltage $\left(V_{T H}\right)$ is given by

$$
\begin{gathered}
V_{T H}=V_{T H 0}+\gamma\left(\sqrt{\left|2 \varnothing_{b}-V_{B S}\right|}-\sqrt{\left|2 \varnothing_{b}\right|}\right) \\
\gamma=\frac{t_{o x}}{\varepsilon_{o x}} \sqrt{2 \varepsilon_{s i} \cdot q \cdot N_{A}} \\
\varnothing_{b}=\frac{k T}{q} \ln \left(\frac{N_{A}}{N_{i}}\right)
\end{gathered}
$$

where $V_{T H 0}$ is the threshold voltage of the device without body bias; $\gamma$ is the coefficient of body effect; $t_{o x}$ is the gate oxide thickness; $\varepsilon_{o x}$ is the dielectric constant of the silicon dioxide; $\varepsilon_{s i}$ is the permittivity of silicon; $\varnothing_{b}$ is the device surface potential on strong inversion; $N_{A}$ is the doping concentration density of the body; $N_{i}$ is the carrier concentration in intrinsic silicon; $k$ is Boltzmann's constant; $q$ is the electric charge and $T$ is the absolute temperature.

\subsection{Reverse Body Bias (RBB)}

Since the mid-1970s, RBB has been widely used in memory cells, in order to reduce the latch-up problem and memory data damage [62] [63]. RBB reduces the 


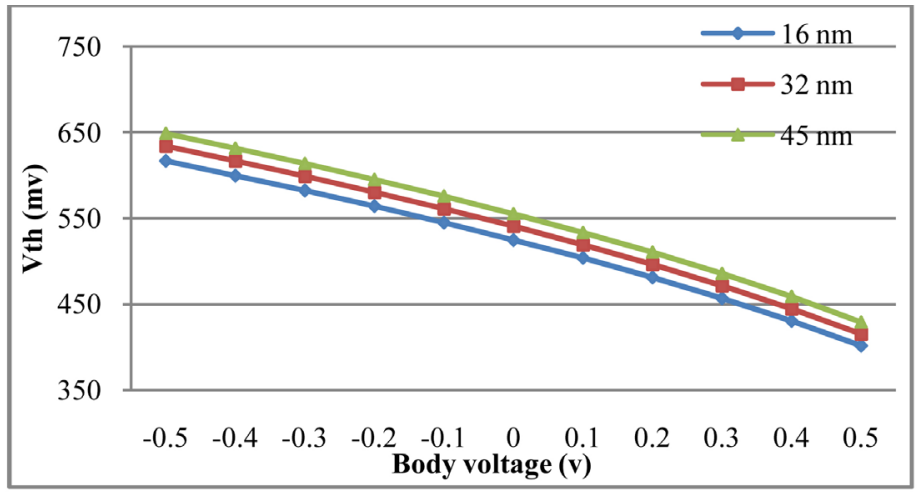

(a)

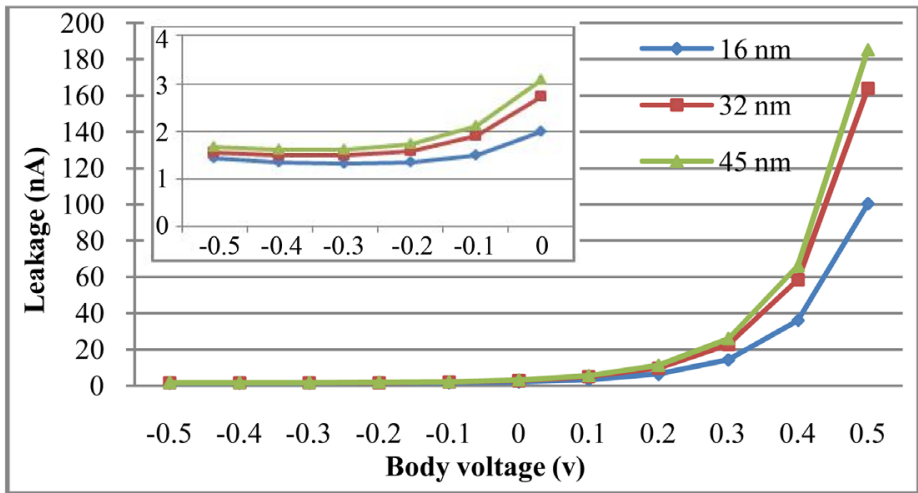

(b)

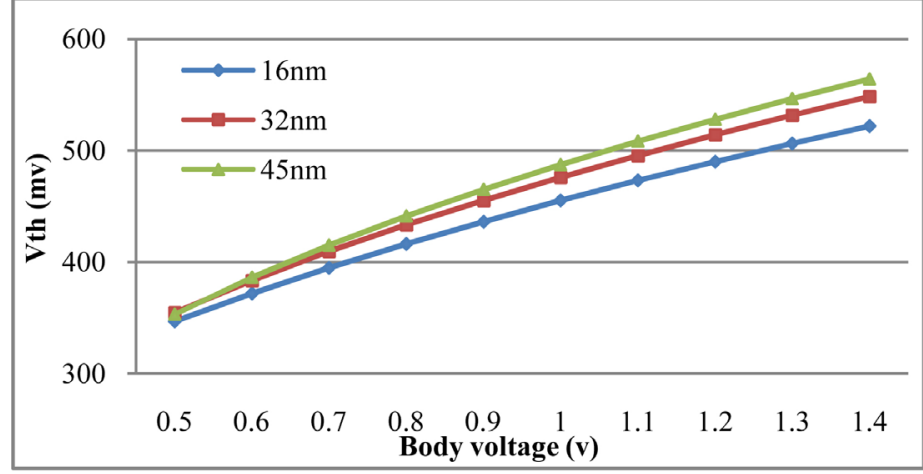

(c)

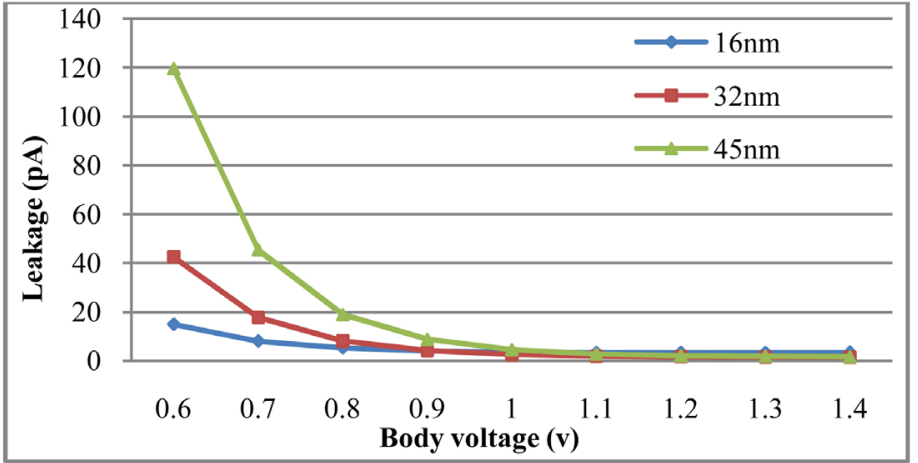

(d)

Figure 5. NMOS body voltage versus (a) Threshold voltage (b) Leakage current. PMOS body voltage versus (c) Threshold voltage (d) Leakage current. 
Table 1. Biasing methods for high- $\mathrm{V}_{\mathrm{TH}}$ PMOS and NMOS [61].

Control voltage (s)
self-reverse
biasing
$V_{B S}$ reverse substrate
driving

sub-threshold leakage while increasing the body voltage. Hence, an optimized RBB reduces the total leakage current. However, the junction leakage is influenced by substrate BTBT rather than the surface BTBT which is also called GIDL [64]. Novel techniques are required to reduce the substrate BTBT leakage in order to use the advantage of RBB. Furthermore, RBB is ineffective for leakage control in short channel devices and also for low- $V_{T H}$ devices functions at high/ room temperature [65] [66].

\subsection{Forward Body Bias (FBB)}

Reverse body bias has larger drain-substrate depletion layer to minimizes the short channel effects. However, threshold variation occurs across a die due to larger depletion layer. Moreover, the short channel devices have lower body coefficient $(\gamma)$, and the channel potential is more affected by drain than by the body due to the DIBL. The short channel effect and DIBL are more sensitive to the low- $V_{T H}$ transistors [67]. Hence the range of body biasing is motivated from RBB to FBB. FBB reduces the threshold voltage of high- $V_{T H}$ devices and improves the circuit performance due to smaller switching capacitance. The FBB devices form larger junction capacitance due to reduced depletion width across the source and drain region [68] [69]. 
However, FBB increases the leakage current due to a source to a body junction is in forward bias. At lower- $V_{T H}$, the short circuit current is increase due to larger junction and gate capacitance. Hence, for optimized design operation at a maximum temperature of $110^{\circ} \mathrm{C}$, the desired forward body voltage is $450 \mathrm{mV}$, with a tolerance of $\pm 50 \mathrm{mV}[70]$.

\subsection{Dual- $V_{T H}$ Technology}

Further improvements in short channel and DIBL can be achieved through dual- $V_{T H}$ technology. A dual- $V_{T H}$ device switches between low- $V_{T H}$ and high- $V_{T H}$. The low- $V_{T H}$ device can be formed by applying FBB and high- $V_{T H}$ device with zero body steps. The complexity associated with a dual- $V_{T H}$ process is reduced because it has a critical fabrication masking process. Need for additional device fabrication with various threshold voltages are eliminated [71].

\subsection{VTCMOS Technique}

In variable threshold CMOS (VTCMOS), a threshold voltage is controlled by the body biasing technique. Different threshold voltages can be achieved by using a self-body biasing transistor (SBT). In active mode, nearly zero body bias is used to achieve high speed. In standby mode, RBB is used to raise threshold voltage, thus minimizes the leakage current. Moreover, in active mode, a little FBB is applied to increase the performance speed while minimizing the short-channel effect. In VTCMOS, additional circuitry is required for body biasing which increases chip area [72] [73].

\subsection{Clamping Diode}

Lijun Zhang et al. proposed a source biasing technique to reduce leakage currents in SRAM cell, as shown in Figure 6. High threshold NMOS transistor M7

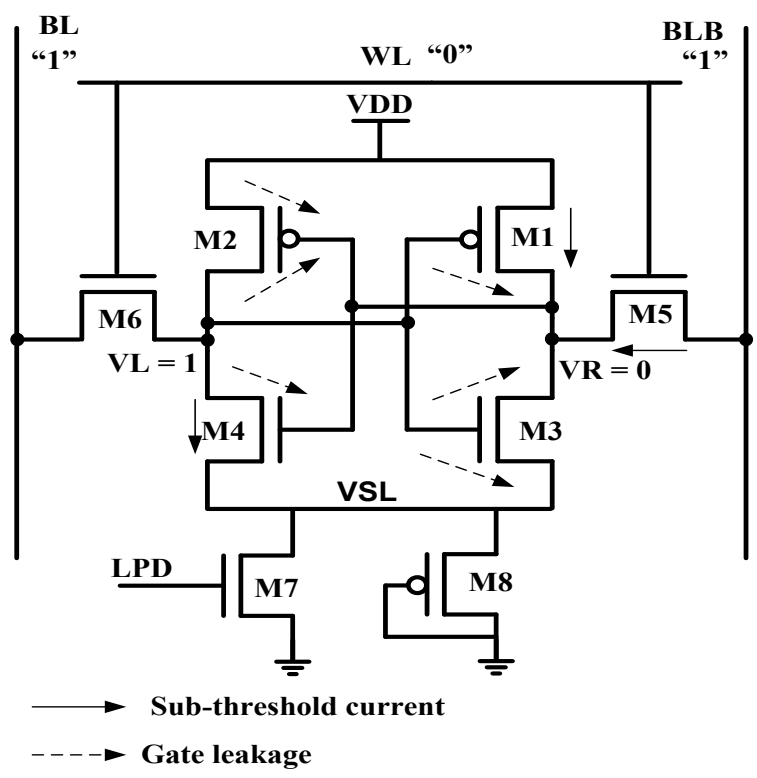

Figure 6. Clamping diode SRAM cell design. 
is connected between SRAM source line $\left(V_{S L}\right)$ and ground terminals. In active mode, M7 will turn on when gate voltage is high and its resistance is small, $V_{S L}$ is equal to the ground and SRAM cell functions in the traditional manner. In standby mode, M7 is turned off, the source voltage $V_{S L}$ increases which reduces the gate and sub-threshold leakage currents. The problem of floating voltage can be resolved by a clamping diode (PMOS transistor gate connected to its drain terminal) which is placed in parallel with the M7 [74].

\subsection{Stacking Technique}

The NMOS stacking transistors are realized with $16 \mathrm{~nm}$, node voltage and leakage current as shown in Figure 7(a) and Figure 7(b). The stacking transistors provide the self-reverse biasing effect:

- Drain-to-source voltage decreases, leading to reduced DIBL current and the sub-threshold leakage current.

- Gate-to-source voltage is less than zero, thus decreasing sub-threshold current exponentially.

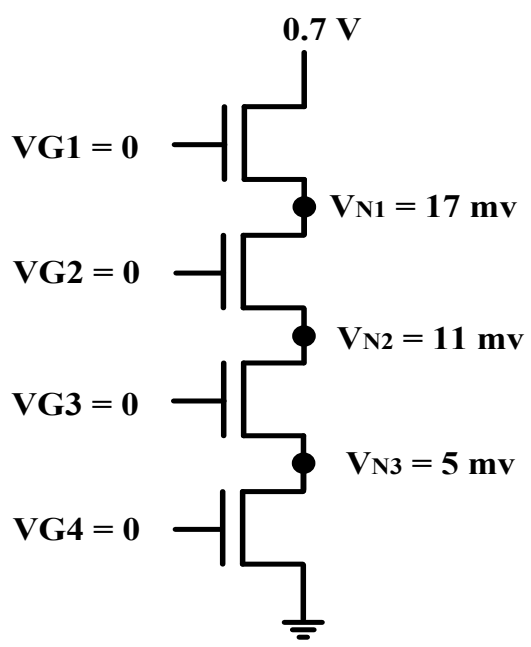

(a)

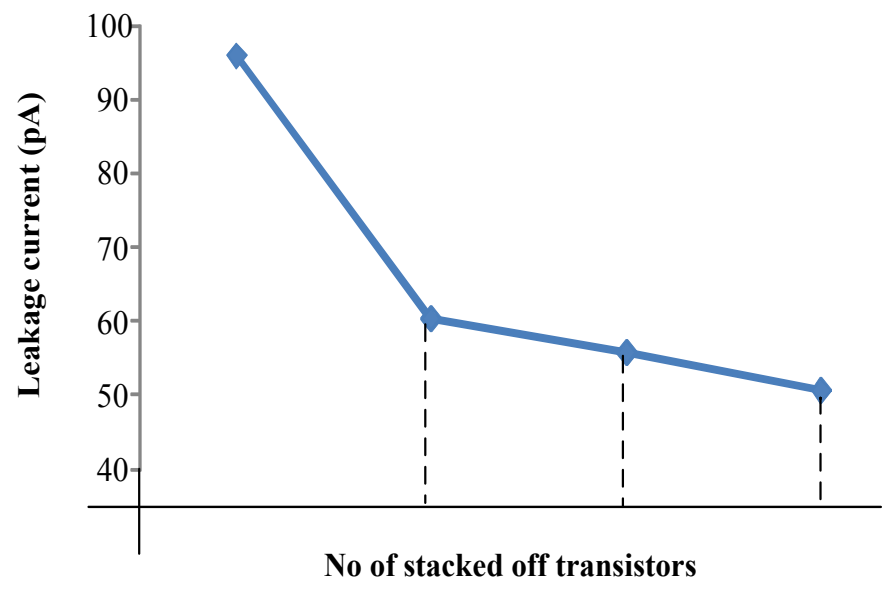

(a)

Figure 7. (a) Stacked transistor (b) leakage current curve. 
- Substrate-to-source voltage is negative, thus increasing the threshold voltage due to body effect, resulting in a decrease in sub-threshold current.

N. K. Shukla et al. proposed a novel P4-SRAM cell consisting of a stacked transistor as shown in Figure 8. When the word line is low, the cell functions as conventional 6T SRAM cell. When the word line is high, transistor P3 andP4will turn off as a result, the self-reverse biasing (SRB) of series connected transistors will reduce the sub-threshold and gate leakage currents [75] [76].

\section{Power Gating Techniques}

Another efficient leakage reduction technique generally used in industry is power gating. In power gating scheme, the leakage currents are almost minimized by introducing the external header and footer transistors. These transistors eliminate the path exiting between $V_{D D}$ to ground when the devices are in quiescent mode [77] [78].

\subsection{Power Gating Scheme with a Sleep Transistor}

To reduce the leakage mechanism in SRAM cell, M. Powell et al. proposed a power gating scheme with a sleep transistor connected in the ground path called Gated- $V_{D D}$, as shown in Figure 9. This design basic principle is to introduce an additional NMOS transistor in the leakage current path present in between the power supply to a ground [79] [80]. The additional transistor is fundamentally "gating" the cell's power supply by "switch on" in the active mode and "switch off" in an idle mode. Gated- $V_{D D}$ scheme significantly reduces the leakage current by maintaining the performance compensation of low power supply and threshold voltage [81] [82].

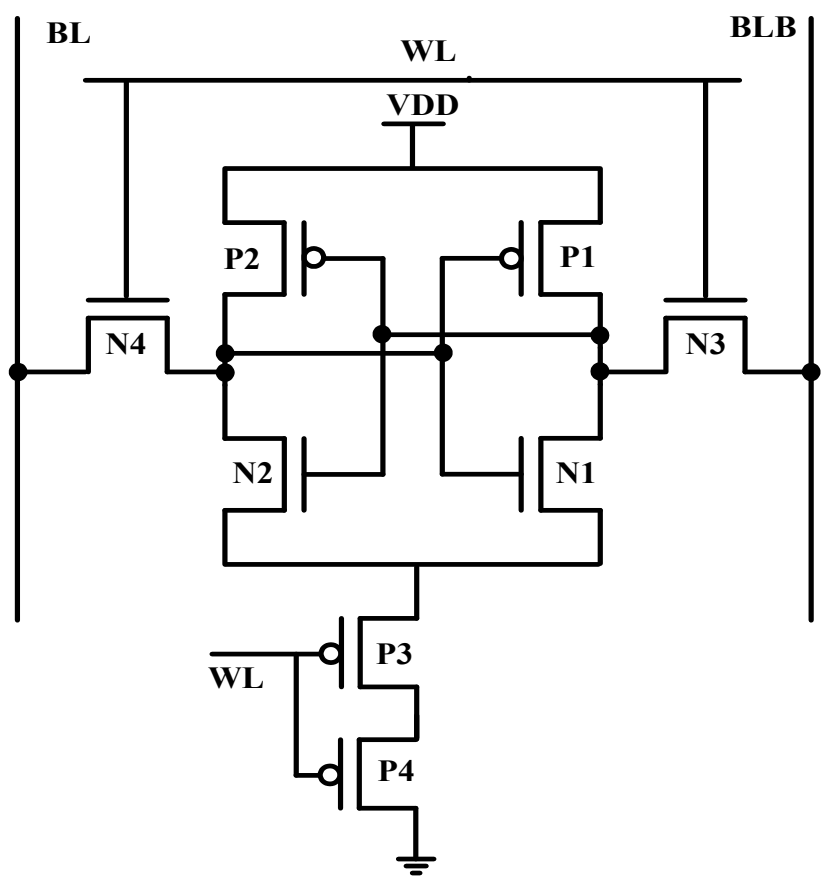

Figure 8. P4-SRAM cell design. 


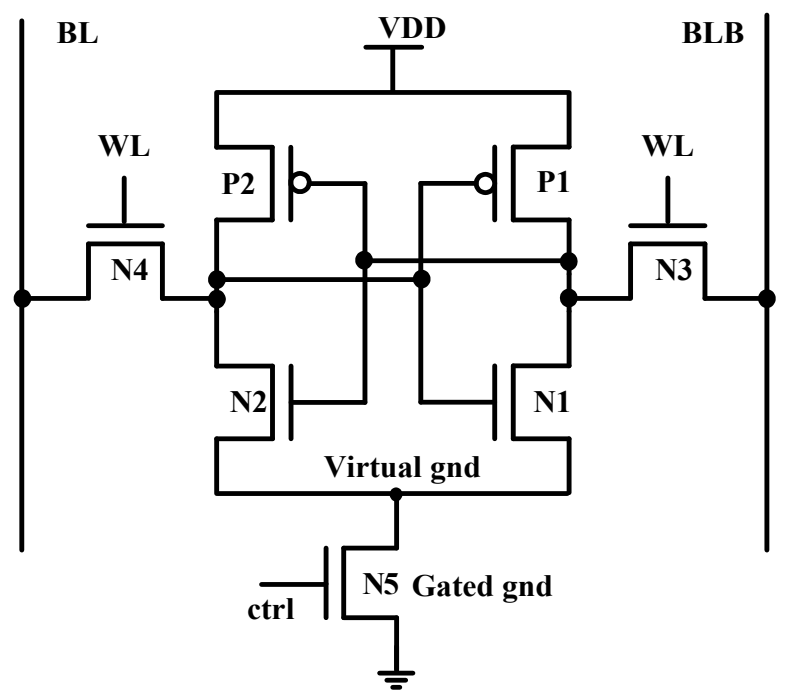

Figure 9. Gated- $V_{D D}$ power gating scheme.

\subsection{Data Retention Gated-Ground (DRG)}

The drawback of the SRAM cell with power gating scheme is the determination of the stored data and the ground gated transistor increases the pull-down (PD) path resistance. To resolve this problem Amit Agarwal et al. proposed a data retention gated-ground (DRG) SRAM cell design to achieve low leakage power, as shown in Figure 10. The ground gated transistor is controlled by the external signal which is connected to the word-line. The leakage current significantly reduced through fundamentally "gating" the cell's power supply by "switch on" in the active mode and "switch off" in an idle mode [83].

\section{3. $N$-Control SRAM Cell with Gated- $V_{D D}$}

Praveen Elakkumanan et al. proposed an $N$-control SRAM cell with gated- $V_{D D}$ and dual threshold voltage to achieve more reduction in leakage power dissipation, as shown in Figure 11. The SRAM cell is designed with low threshold transistor to attain high speed. Additional sleep transistors are designed with high$V_{T H}$ transistor to minimize leakage power, high- $V_{T H}$ transistor are show with doted circles [84].

\subsection{Diode-Connected PMOS Bias Transistor}

Ankur Goel et al. proposed a power gating scheme along with post-silicon trim of the SRAM cell, as shown in Figure 12(a). This technique provides many ways to trim the source voltage across SRAM cell ranging from 50 to $150 \mathrm{mV}$. Sector-based power gating has been presented which allows the leakage current reduction while SRAM is in active mode [85]. The PMOS transistor acts as a diode by connecting the source and gate terminal together. This process is termed as the self-biasing technique and it controls the virtual ground [86].

However, the self-biasing technique used in nanometre technology suffers from three problems. First, an additional self-biasing transistor (SBT) requires 


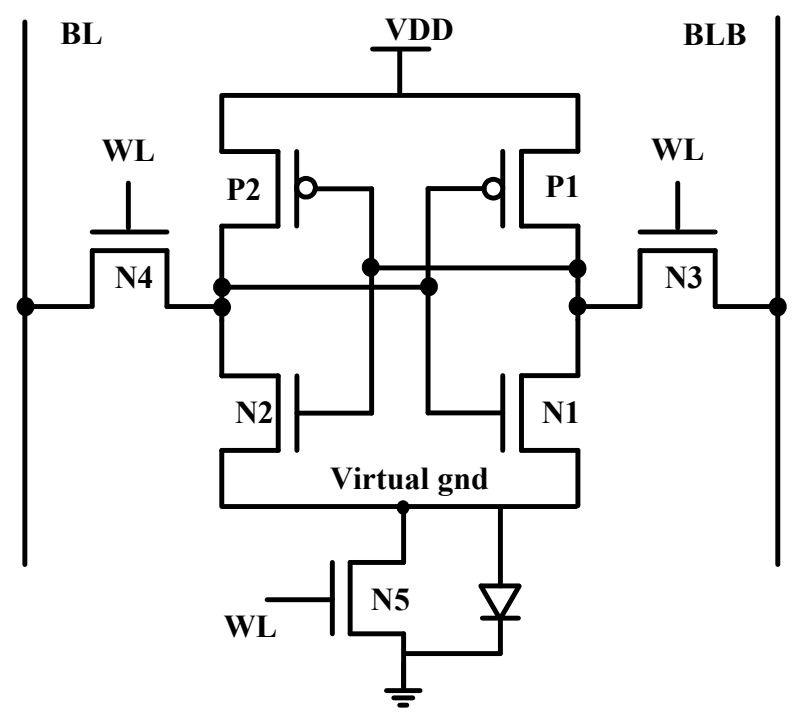

Figure 10. DRG SRAM cell design.

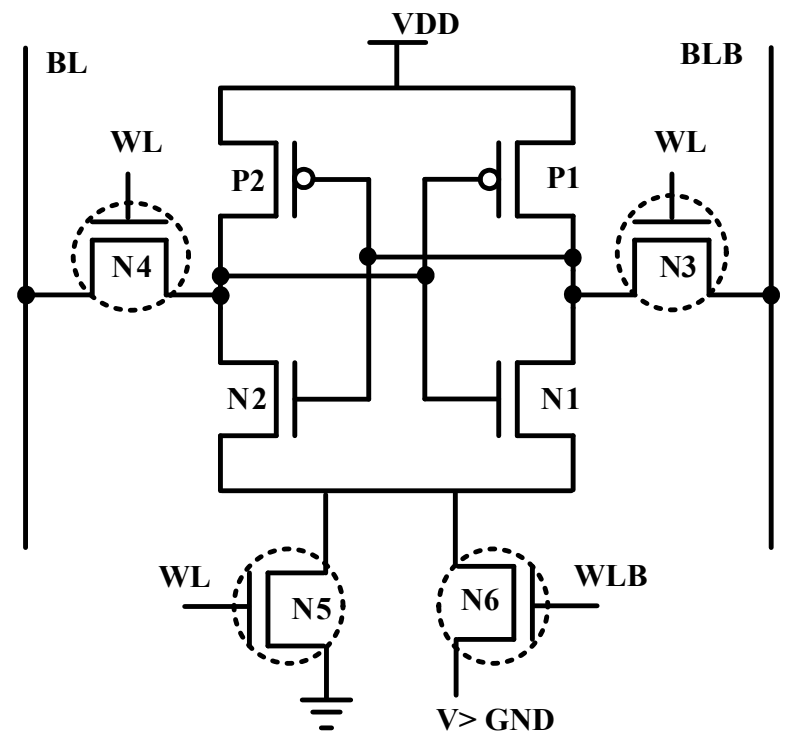

Figure 11. NC-SRAM cell design.

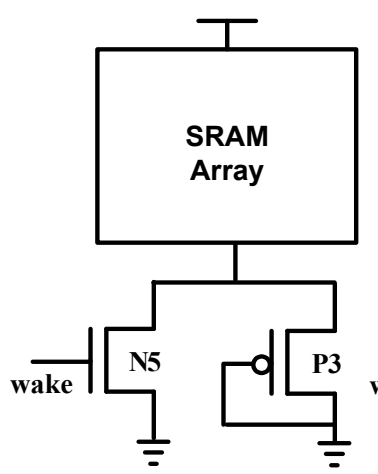

(a)

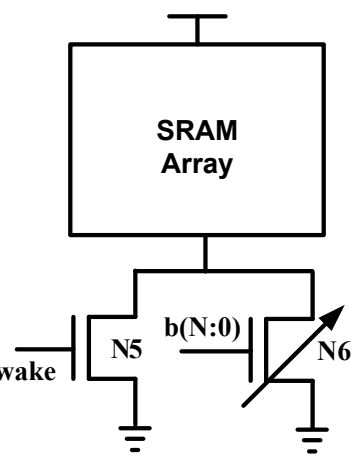

(b)

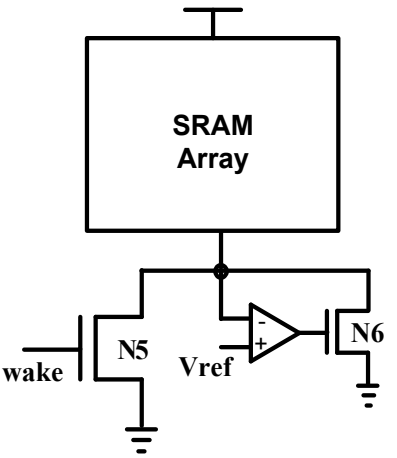

(c)

Figure 12. The SRAM cell with (a) diode-connected PMOS bias transistor (b) programmable bias transistor (c) active feedback with Op-Amp-based control. 
extra area which is around 5\%. Second, these schemes fail to carry out the correct mechanism for the modified source voltage. Third, increasing the virtual ground voltage has serious consequences such as negative bias temperature instability (NBTI)/positive bias temperature instability (PBTI) [87] [88] [89].

\subsection{Programmable Bias Transistor}

Kevin Zhang et al. proposed a programmable bias transistor (PBT) to control the SRAM virtual ground in standby mode, as shown in Figure 12(b). PBT design is more effective in solving the post-silicon trimming issues and it has good control in a virtual ground. PBT provides two main advantages. First, the transistor biasing settings (virtual ground voltage) can be adjusted to achieve maximum leakage current reduction. Second, various biasing settings can be randomly chosen at various power supplies to provide an effective design under dissimilar voltage environments. However, they have some issues regarding the die-to-die (D2D), within die (WID) and induced temperature variations [90].

\subsection{Active Feedback with 0p-Amp-Based Control}

To overcome the variations in a die, another efficient technique has been proposed with an active feedback op-amp, as shown in Figure 12(c). A sleep transistor with active feedback op-amp bias reduces the standby power of the last level caches (LLCs) under all circumstances throughout the lifespan of the processor [91]. The main disadvantage of this technique is the DC power consumed by the op-amp that needs to be replicated along with each data. Further, this technique increases the SRAM cell area and it is noticeable in CMOS nanometre technology.

\subsection{Diode and on Transistor Interchangeable Technique}

Suhwan Kim et al. proposed a novel design which consists of "on transistor" and "power gating diode". This design is termed as "diode and on transistor interchangeable technique". This technique functions in two modes, light sleep mode and shutdown mode. In light sleep mode SRAM cell, data will be retained and voltage around SRAM memory must be greater than the minimum data retention voltage. It is also referred to as leakage saving mode which is shown in Figure 13(a). In shutdown mode, SRAM memory data need not necessarily be recalled and the virtual ground level will be raised to attain enhanced leakage power saving. The shutdown mode design is as shown in Figure 13(b), which has modified control logic transistor. The modified design can be operated in both light sleep and shutdown modes [92].

\section{Multi-Threshold Design}

Generally, SRAM cell contains six transistors with symmetrical configuration and normally they maintain same threshold voltage. MTCMOS is one of the prominent topologies to minimize the leakage power [93] [94]. By using an appropriate multi-threshold transistor result in a low leakage SRAM cell without 


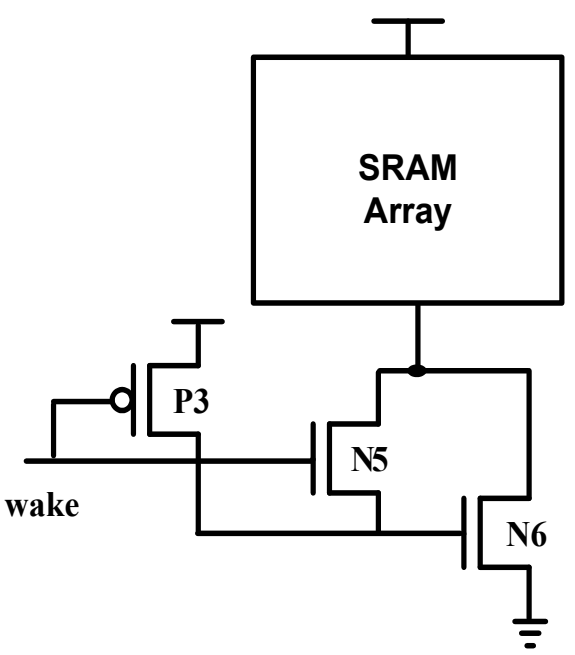

(a)

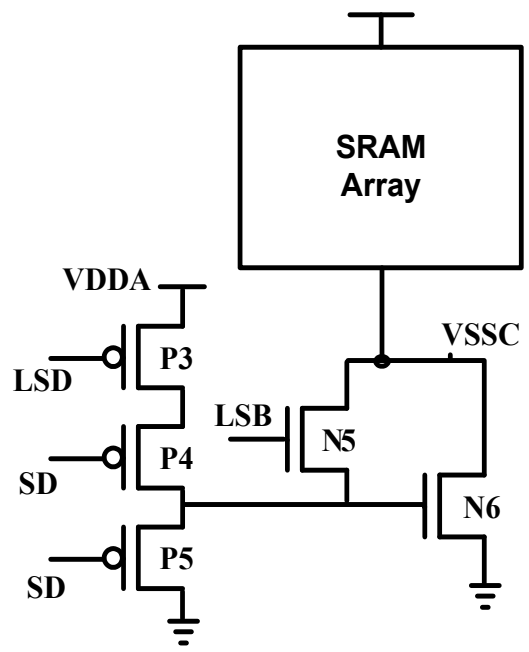

(b)

Figure 13. (a) Light sleep mode (b) Shutdown mode.

degrading the read/write performance. A suitable solution for having the low power SRAM cell with high performance and constancy is to implement asymmetrical designs [95] [96].

\subsection{Asymmetrical Design}

Asymmetrical cells can be designed in two different methods. The first approach is to have all original 6T-cell with different threshold voltages for selected transistors. The second approach is to add an extra transistor to the traditional 6Tcell. Asymmetrical SRAM cells designs are mainly based on the state of the cell, choose a state "0" or "1" and change the necessary transistor with high- $V_{T H}$ transistors in order to minimize the leakage current. N. Azizi et al. proposed several designs of asymmetrical SRAM cells, with main focus on state "0", as it plays important role in storing the data. These architectures reduce the leakage current in the " 0 " state and probably they do not affect the " 1 " state.

\subsection{Basic Asymmetric (BA)}

The first design is named as Basic Asymmetric (BA) as shown in Figure 14(a). In this design $\mathrm{N} 1, \mathrm{~N} 4$, and $\mathrm{P} 2$ transistors are replaced with high- $V_{T H}$ transistors, which is shown in doted circles. This SRAM cell reduces leakage power by $70 X$ when the cell stores " 0 " and maintains the same leakage in case "1" is stored. However, the read access time is reduced (the bit-line discharge time is increased w.r.t traditional cell) due to high- $V_{T H}$ transistors (N1 and N4). P1 and P2 transistor do not affect the read access time since the bit lines are discharged through two NMOS transistors.

An asymmetrical SRAM cell transistor P1 is modified with high- $V_{T H}$ as shown in Figure 14(b). This design reduces the leakage current by $1.6 X$ when the cell stored data is " 1 " as compared to traditional design and the BA design. It reduces the leakage power reduction by $70 X$ when the cell stores data " 0 ". As another modification, transistor $\mathrm{N} 2$ is designed with high- $V_{T H}$ as shown in Figure 14(c). 


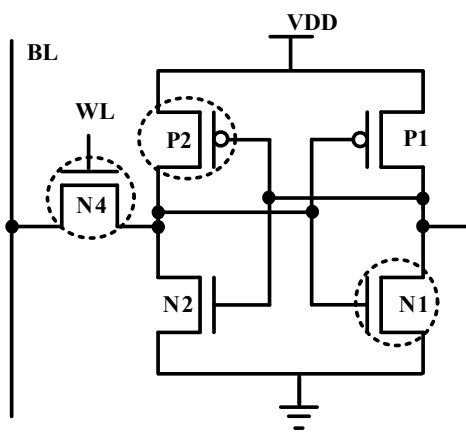

(a)

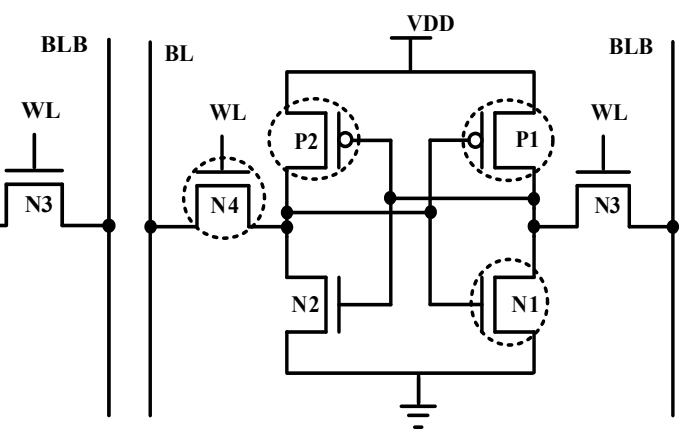

(b)

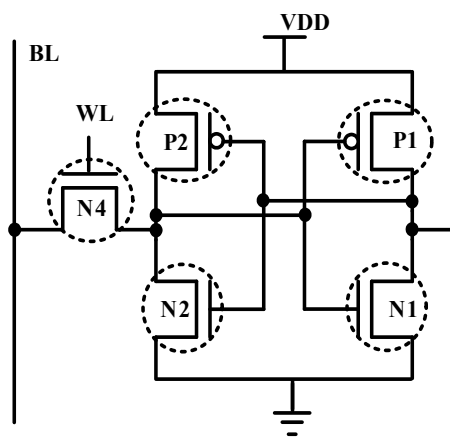

(c)

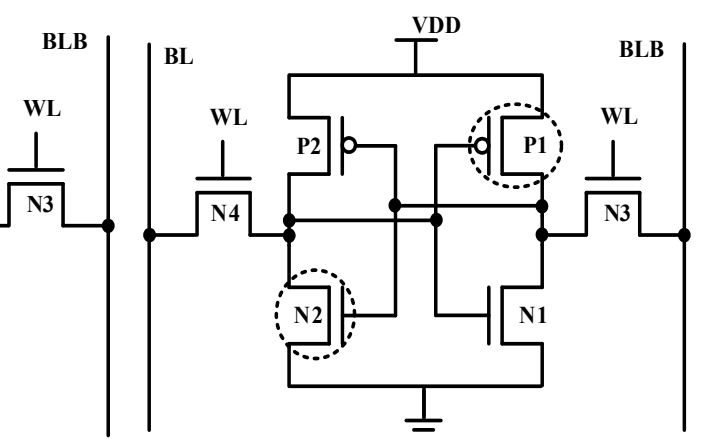

(d)

Figure 14. SRAM cell designs (a) Basic asymmetric (b) P1 is modified (c) Another modification (d) Special precharge.

Asymmetric cells have different discharge timings for bit-line and bit-line-bar. In this case, sense amplifier should match the read access time of slow side to the fast access side. This design further minimizes the leakage power by $7 X$ when cell stored data " 1 ". To reduce the read access time delay, an asymmetrical SRAM cell needs to be modified.

The special precharge SRAM cell is as shown in Figure 14(d), where only P1, $\mathrm{N} 2$ transistors are replaced with high- $V_{T H}$ and the remaining with low- $V_{T H}$ transistors. Initially bit-line is precharge to $V_{D D}$ but in steady state bit-line needs to be kept at ground. This design attains leakage reduction $83 X$ when the cell is stores data " 0 " and no reduction in leakage when cell stored data " 1 ". The bit-line times decreased by $12 X$ as compared to traditional cell [97] [98].

\subsection{Effect of MTCMOS on RBL Sensing}

A T Do et al. have proposed a decoupled 8T SRAM cell to achieve larger bit-line data sensing margin which is used in ultra-low power SRAM cells due to enhanced stability. The read word line performs the read operation by enabling N7 and the read bit lines are conditionally discharged according to the SRAM cell data. However, due to aggressive scaling of device parameters, the read bit-line leakage current increase which is almost comparable with the SRAM cell read current. The read bit-line data discharging depends on the cell read access current and read bit-line leakage current [99] [100]. In order to overcome these limitations, a leakage control bit-line scheme was proposed in read access path 
with a high- $V_{T H}$ and low- $V_{T H}$ transistors which are shown in Figure 15. In the super-threshold region, high- $V_{T H}$ transistors design achieves good Ion and Ioff current ratio. Low- $V_{T H}$ transistor design had larger read bit-line swing along with smaller read bit-line data sensing margin due to sub-threshold leakage current [101] [102].

\subsection{Bit Line Boosting Current Scheme}

Bo Wang et al. proposed a 9T-MTCMOS SRAM cell, which consists of additional 3T read access bit-line, as shown in Figure 16(a). This design reduces the leakage current while increasing read bit-line sensing margin. A 9T SRAM cell consists of a basic $6 \mathrm{~T}$ cell and the read access port contains 3T NMOS. All transistors in 6T-SRAM cell are designed with high- $V_{T H}$, which are shown in thick lines and the read access bit-line 3T NMOS are designed with low- $V_{T H}$ to achieve very high performance through improved bit-line sensing margin. However, the cell bit line leakage is more than the cell read access current at higher temperatures [103] [104].

A. Teman et al. have proposed a 9T SRAM cell with a unique structure of supply feedback methodology for low voltage operation. In this 9T SRAM design, the supply voltage feedback transistor gate terminal is connected to the latch output to weaken the pull-up network of SRAM cell in a write operation, as shown in a Figure 16(b). The main advantage of this feedback is to maintaining

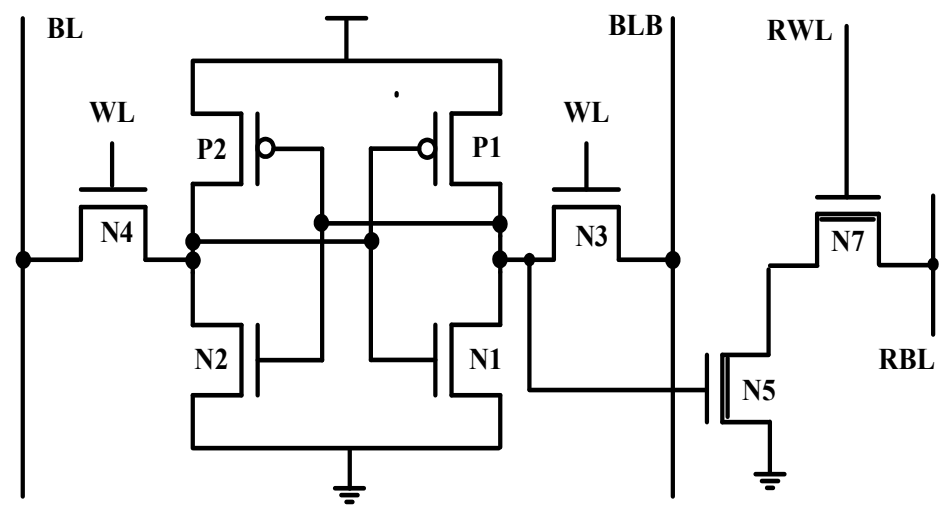

(a)

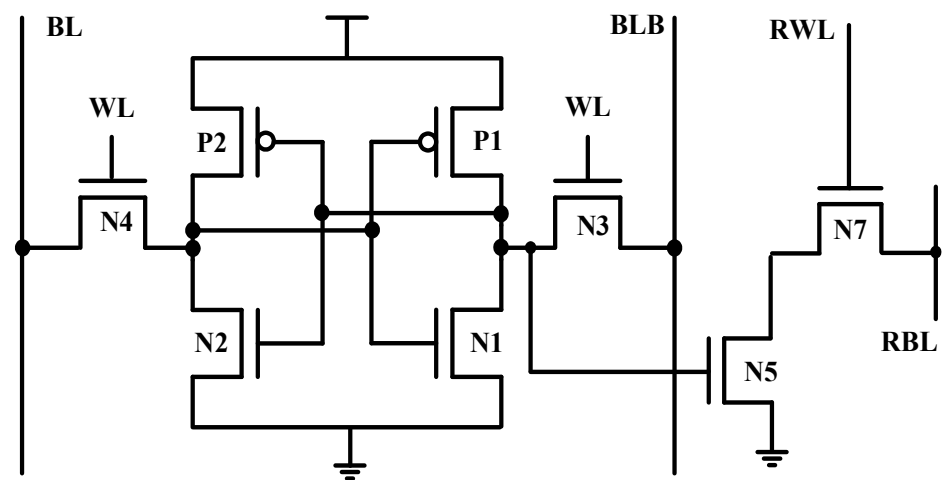

(b)

Figure 15. RBL sensing (a) high- $V_{T H}$ (b) low- $V_{T H}$. 


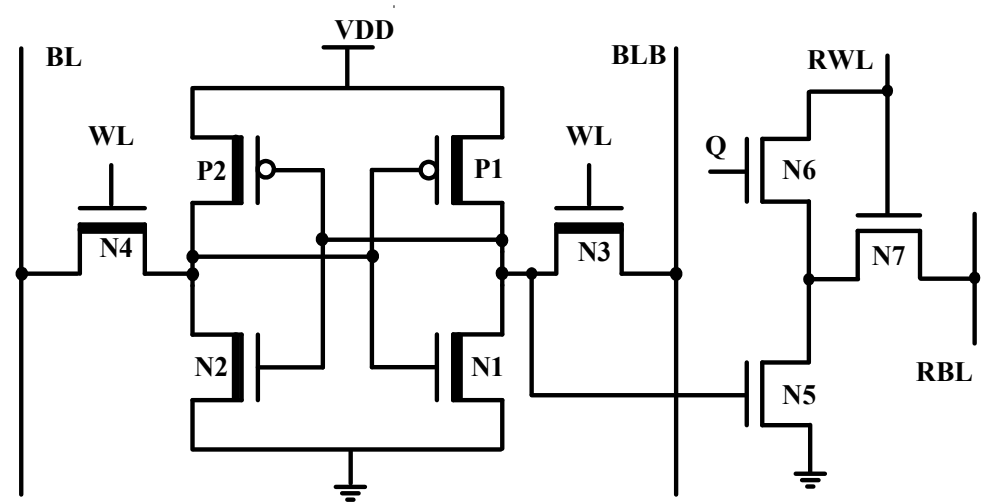

(a)

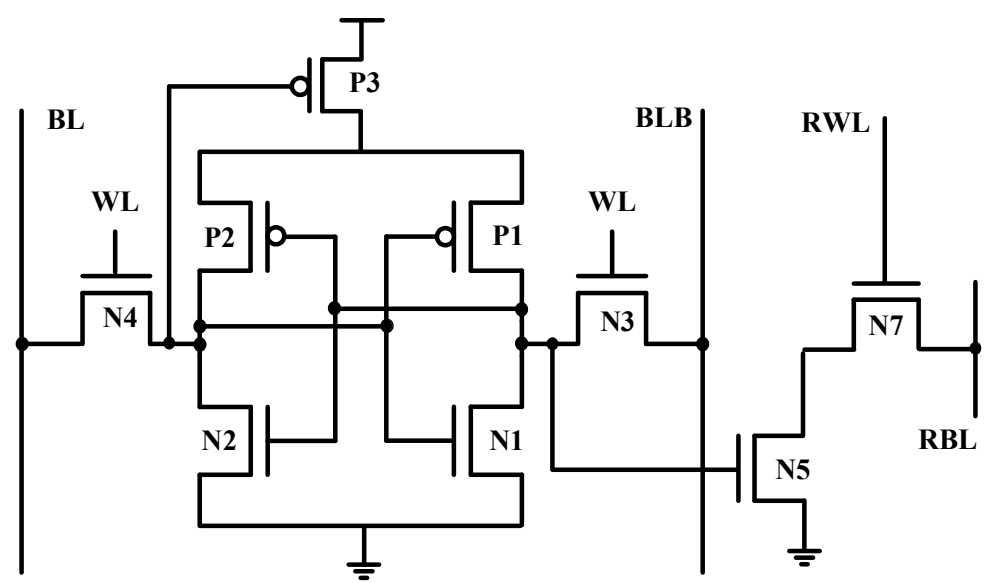

(b)

Figure 16. The SRAM cell (a) 9T MTCMOS design (b) 9F-Supply feedback design.

improved write margins and functionality, even though the PMOS transistors are stronger than the NMOS transistors [105] [106].

\section{Conclusion}

In this paper, the origin of leakage currents in a short-channel device has been discussed when a device is in conduction and non-conduction state. The various leakage control techniques proposed for low power SRAM cell architecture are presented. Classification of leakage minimization approaches analyzed based on their fundamental design and mechanism, such as biasing techniques, power gating techniques and multi-threshold techniques. The biasing techniques focus on changing the threshold voltage in order to control sub-threshold leakages. RBB design has reduced the leakage but it has consequences in terms of performance. Optimized FBB design can help to achieve high performance with low power dissipation. The key emphasis of power gating technique is on leakage path that exists in the circuit. Extra circuitry is added to create the virtual ground in leakage path to control the leakage currents. The multi-threshold design has the concept of asymmetrical design with a high- $V_{T H}$ transistor in leakage path and a low- $V_{T H}$ transistor for fast access. All these techniques have 
Table 2. Comparison of various low power techniques.

\begin{tabular}{|c|c|c|c|c|}
\hline Technique & $\begin{array}{l}\text { No. of } \\
\text { MOSs }\end{array}$ & Merits & Demerits & Limitations \\
\hline \multicolumn{5}{|c|}{ Biasing techniques } \\
\hline $\begin{array}{c}\text { Reverse body biasing } \\
\text { [57] [58] [63] [65] [107] [108] }\end{array}$ & $6 \mathrm{~T}$ & $I_{\text {Sub-th }} \downarrow \downarrow$ & $\begin{array}{c}I_{\text {Junction }} \uparrow, \text { Large transition } \\
\text { delay }\end{array}$ & $\begin{array}{c}\text { Sensitive to } V_{T H} \text { variation \& } \\
\text { GIDL }\end{array}$ \\
\hline $\begin{array}{l}\text { Forward body bias, } \\
\text { [59] [60] [68] [69] [70] }\end{array}$ & $6 \mathrm{~T}$ & $\begin{array}{c}\text { Small switching capacitance, } \\
\text { speed } \uparrow\end{array}$ & $\begin{array}{l}\text { Process complexity, } \\
\text { Area overhead }\end{array}$ & Sensitive to SCE \& DIBL \\
\hline $\begin{array}{l}\text { Source-biasing } \\
{[61][109][110]}\end{array}$ & $6 \mathrm{~T}$ & $I_{\text {Sub-th }}, I_{\text {Gate }} \downarrow \downarrow$ & Delay penalty $\left(\tau_{\mathrm{PD}} \uparrow\right)$ & $\begin{array}{l}\text { Impact on soft error rate } \\
\text { (SER) }\end{array}$ \\
\hline Dual- $\mathrm{V}_{\mathrm{TH}}[71]$ & $6 \mathrm{~T}$ & $\begin{array}{c}\text { Improved short-channel, } \\
\text { DIBL }\end{array}$ & Switching & Need of FBB \\
\hline VTCMOS [72] [73] & $6 \mathrm{~T}$ & Low leakage, high speed & $\begin{array}{l}\text { Additional circuitry need to } \\
\text { control the threshold }\end{array}$ & $\begin{array}{l}\text { Need to control the } \\
\text { body bias }\end{array}$ \\
\hline Clamping diode [74] & $8 \mathrm{~T}$ & $I_{\text {Sub-th }}, I_{\text {Gate }} \downarrow$ & Delay penalty $\left(\tau_{\mathrm{PD}} \uparrow\right)$ & Floating voltage at $V_{S L}$ \\
\hline $\begin{array}{l}\text { Stacking body biasing (SRB) } \\
\text { [75] }\end{array}$ & $8 \mathrm{~T}$ & $I_{\text {Sub-th }}, I_{\text {Gate }} \downarrow$ & $\begin{array}{l}\text { Delay increase, } \\
\text { Area overhead }\end{array}$ & $V_{T H} \uparrow$ due to body effect \\
\hline \multicolumn{5}{|c|}{ Power gating techniques } \\
\hline $\begin{array}{l}\text { Ground gated, sleep transistor } \\
{[799][80][82]}\end{array}$ & $8 \mathrm{~T}$ & $I_{\text {Sub-th }}, I_{\text {Gate }} \downarrow$ & $\begin{array}{c}\text { virtual ground } \uparrow \uparrow, \mathrm{PD} \text { path } \\
\text { resistance } \uparrow\end{array}$ & $\begin{array}{l}\text { process-induced } V t \\
\text { variation, data } \\
\text { retention problem }\end{array}$ \\
\hline $\begin{array}{l}\text { Data retention gated-ground } \\
\qquad[83]\end{array}$ & $7 \mathrm{~T}$ & data retention, low leakage & Delay penalty & $\begin{array}{l}\text { Need of External } \\
\text { control signal }\end{array}$ \\
\hline $\begin{array}{c}\mathrm{N} \text {-control with gated- } \mathrm{V}_{\mathrm{DD}} \\
\text { [84] }\end{array}$ & $8 \mathrm{~T}$ & leakage power, high speed & Dual-threshold & $\begin{array}{l}\text { Need to control virtual } \\
\text { ground }\end{array}$ \\
\hline Diode-connected [85] [88] & $8 \mathrm{~T}$ & $I_{\text {Sub-th }}, I_{\text {Gate }} \downarrow$ & $\begin{array}{l}\text { SNM } \downarrow \text {, sensitive to } \\
\text { NBTI/PBTI }\end{array}$ & Data recalled, need of SBT \\
\hline $\begin{array}{l}\text { programmable bias transistor } \\
\qquad[90]\end{array}$ & $8 \mathrm{~T}$ & $\begin{array}{l}\text { Good control in virtual } \\
\text { ground, }\end{array}$ & $\begin{array}{l}\text { die-to-die, within die } \\
\text { temperature variations }\end{array}$ & Need of PBT \\
\hline Active feedback op-amp [91] & $\begin{array}{c}7 \mathrm{~T}+ \\
\text { op-amp }\end{array}$ & $\begin{array}{c}\text { Standby power } \downarrow \text {, die-to-die } \\
\text { leakage } \downarrow\end{array}$ & $\begin{array}{l}\text { DC power consumed } \\
\text { by the op-amp, area }\end{array}$ & Need of op-amp \\
\hline Light sleep mode [92] & $9 \mathrm{~T}$ & $\begin{array}{l}\text { Low leakage power, } \\
\text { data retained }\end{array}$ & $\begin{array}{c}\text { performance } \\
\text { degradation, area }\end{array}$ & $\begin{array}{c}\text { Memory voltage }>\text { min. data } \\
\text { retention voltage }\end{array}$ \\
\hline Shutdown mode design [92] & $11 \mathrm{~T}$ & Low leakage power & $\begin{array}{l}\text { Increased virtual } \\
\text { ground, area }\end{array}$ & $\begin{array}{l}\text { Need more no. of control } \\
\text { inputs }\end{array}$ \\
\hline \multicolumn{5}{|c|}{ Multi-threshold design } \\
\hline Basic Asymmetric [97] [98] & $6 \mathrm{~T}$ & reduces leakage power by $70 x$ & bit-line discharge time $\uparrow$ & Need of high- $V_{T H}$ \\
\hline $\begin{array}{c}\text { High- } \mathrm{V}_{\mathrm{TH}} \text { on RBL Sensing } \\
{[100]}\end{array}$ & $8 \mathrm{~T}$ & good $I_{o n}$ and $I_{o f f}$ current ratios & Read access time $\uparrow$ & $\begin{array}{l}\text { Small prominent in near and } \\
\text { sub-threshold region }\end{array}$ \\
\hline $\begin{array}{c}\text { Low- } \mathrm{V}_{\mathrm{TH}} \text { on RBL Sensing } \\
{[100][102]}\end{array}$ & $8 \mathrm{~T}$ & larger read bit-line swing & $I_{\text {sub-th }} \uparrow$ & $\begin{array}{l}\text { smaller read bit-line data } \\
\text { sensing margin }\end{array}$ \\
\hline Bit-line boosting [103] [104] & $9 \mathrm{~T}$ & $\begin{array}{c}\text { low leakage, read bit-line } \\
\text { sensing margin } \uparrow\end{array}$ & $\begin{array}{c}\text { Data dependent bit } \\
\text { line- leakage } \uparrow\end{array}$ & $\begin{array}{l}\text { Data effected due to } \\
\text { Temperature variations }\end{array}$ \\
\hline $\begin{array}{l}\text { Supply Feedback approach } \\
\text { [105] [106] }\end{array}$ & $9 \mathrm{~T}$ & $\begin{array}{l}\text { Improved write margin \& } \\
\text { functionality }\end{array}$ & Performance degradation & $\begin{array}{l}\text { Need to maintain a } \\
\text { reasonable SNM. }\end{array}$ \\
\hline
\end{tabular}


the single objective of reducing the leakage in the nano-scale era. Most of these techniques focused on the sub-threshold leakage minimization. However, some of the techniques emphasize on retaining the data during the standby mode. A brief summary of different leakage control schemes with their merits and demerits along with the limitations by using these schemes is presented in Table 2. The low power SRAM cell designs presented in this paper will be helpful for researches to work towards emerging power-efficient memory designs for ultralow power applications. We presented only three main techniques for a basic SRAM cell. Simulation analysis has been shown for basic leakage currents in a device; these are the limitations of this paper.

\section{References}

[1] Mead, C.A. (1994) Scaling of MOS Technology to Submicroometer Feature Sizes. Analog Integrated Circuits and Signal Processing, 6, 9-25. https://doi.org/10.1007/BF01250732

[2] Taur, Y., Member, S., Buchanan, D.A., Chen, W.E.I., Frank, D.J., Ismail, K.E. and Wong, H. (1997) CMOS Scaling into the Nanometer Regime. Proceedings of the IEEE, 85, 486-504. https://doi.org/10.1109/5.573737

[3] Breed, A.A. and Roenker, K.P. (2008) Comparison of the Scaling Characteristics of Nanoscale SOI N-Channel Multiple-Gate MOSFETs. Analog Integrated Circuits and Signal Processing, 56, 135-141. https://doi.org/10.1007/s10470-007-9129-6

[4] Foty, D. (1999) Perspectives on Analytical Modeling of Small Geometry MOSFETs in SPICE for Low Voltage/Low Power CMOS Circuit Design. Analog Integrated Circuits and Signal Processing, 21, 229-252. https://doi.org/10.1023/A:1008373903657

[5] Zou, L. and Larsen, T. (2012) Modeling of Substrate Leakage Currents in a HighVoltage CMOS Rectifier. Analog Integrated Circuits and Signal Processing, 71, 231 236. https://doi.org/10.1007/s10470-011-9633-6

[6] Kaizerman, A., Fisher, S. and Fish, A. (2013) Subthreshold Dual Mode Logic. IEEE Transactions on Very Large Scale Integration (VLSI) Systems, 21, 979-983. https://doi.org/10.1109/TVLSI.2012.2198678

[7] Bol, D., Ambroise, R., Flandre, D. and Legat, J.-D. (2009) Interests and Limitation of Technology Scaling for Subthreshold Logic. IEEE Transactions on Very Large Scale Integration (VLSI) System, 17, 1508-1519. https://doi.org/10.1109/TVLSI.2008.2005413

[8] Sun, S.W. and Tsui, P.G.Y. (1995) Limitation of CMOS Supply-Voltage Scaling by MOSFET Threshold-Voltage Variation. IEEE Journal of Solid-State Circuits, 30, 947-949. https://doi.org/10.1109/4.400439

[9] De, V. and Borkar, S. (1999) Technology and Design Challenges for Low Power and High Performance. Proceeding of International Symposium on Low Power Electronics and Design, San Diego, CA, 16-17 August 1999, 163-168. https://doi.org/10.1145/313817.313908

[10] Rao, R., Srivastava, A., Blaauw, D. and Sylvester, D. (2004) Statistical Analysis of Subthreshold Leakage Current for VLSI Circuits. IEEE Transactions on Very Large Scale Integration (VLSI) Systems, 12, 131-139. https://doi.org/10.1109/TVLSI.2003.821549

[11] Ki, K. and Kim, K.Y. (2009) Statistical Timing and Leakage Power Analysis of PDSOI Digital Circuits. Analog Integrated Circuits and Signal Processing, 60, 127-136. 
https://doi.org/10.1007/s10470-008-9220-7

[12] Xue, J., Li, T., Deng, Y. and Yu, Z. (2010) Full-Chip Leakage Analysis for $65 \mathrm{~nm}$ CMOS Technology and Beyond. Integration, the VLSI Journal, 43, 353-364. https://doi.org/10.1016/j.vlsi.2010.05.002

[13] Keshavarzi, A., Roy, K., Member, S. and Hawkins, C.F. (2000) Intrinsic Leakage in Deep Submicron CMOS ICs-Measurement-Based Test Solutions. IEEE Transactions on Very Large Scale Integration (VLSI) Systems, 8, 717-723. https://doi.org/10.1109/92.902266

[14] Lorenzo, R. and Chaudhury, S. (2016) Review of Circuit Level Leakage Minimization Techniques in CMOS VLSI Circuits. IETE Technical Review, 33, 1-23. https://doi.org/10.1080/02564602.2016.1162116

[15] Henson, W.K., Yang, N., Kubicek, S., Vogel, E.M., Wortman, J.J., Member, S., et al. (2000) Analysis of Leakage Currents and Impact on Off-State Power Consumption for CMOS Technology in the 100-nm Regime. IEEE Transactions on Electron Devices, 47, 1393-1400. https://doi.org/10.1109/16.848282

[16] Bikki, P. and Karuppanan, P. (2016) Analysis of Low Power and Small Swing SelfBiasing CMOS Design. Fareast Journal of Electronics and Communication, 3, 245 261. https://doi.org/10.17654/ECSV3PI16245

[17] Fjeldly, T.A., Member, S. and Shur, M. (1993) Threshold Voltage Modeling and the Subthreshold Regime of Operation of Short-Channel. IEEE Transactions on Electron Devices, 40, 137-145. https://doi.org/10.1109/16.249436

[18] Tsang, T.K., El-gamal, N.M., Iniewski, K., Townsend, K.A., Haslett, J.W. and Wang, Y. (2007) Current Status of CMOS Low Voltage and Low Power Wireless IC Designs. Analog Integrated Circuits and Signal Processing, 53, 9-18. https://doi.org/10.1007/s10470-006-9019-3

[19] Serra-Graells, F. and Huertas, J.L. (2003) 1 V CMOS Subthreshold Log Domain PDM. Analog Integrated Circuits and Signal Processing, 34, 183-187. https://doi.org/10.1023/A:1022545414777

[20] Singh, S.K. and Kaushik, B.K. (2013) A Novel Approach to Reduce Leakage Current in ULP SRAM. IETE Technical Review, 59, 704-708. https://doi.org/10.4103/0377-2063.126968

[21] Prasad, G. and Anand, A. (2015) Statistical Analysis of Low-Power SRAM Cell Structure. Analog Integrated Circuits and Signal Processing, 82, 349-358. https://doi.org/10.1007/s10470-014-0463-1

[22] Jovanovic, B., Brum, R.M. and Torres, L. (2014) Evaluation of Hybrid MRAM/ CMOS Cells for "Normally-Off and Instant-On" Computing. Analog Integrated Circuits and Signal Processing, 81, 607-621. https://doi.org/10.1007/s10470-014-0427-5

[23] Lo, C.H. and Huang, S.Y. (2011) P-P-N Based 10T SRAM Cell for Low-Leakage and Resilient Subthreshold Operation. IEEE Journal of Solid-State Circuits, 46, 695-704. https://doi.org/10.1109/JSSC.2010.2102571

[24] Zhang, L.-J., Wu, C., Ma, Y.-Q., Zheng, J.-B. and Mao, L.-F. (2011) Leakage Power Reduction Techniques of $55 \mathrm{~nm}$ SRAM Cells. IETE Technical Review, 28, 135-145. https://doi.org/10.4103/0256-4602.78105

[25] Roy, K., Mukhopadhyay, S. and Mahmoodi-Meimand, H. (2003) Leakage Current Mechanisms and Leakage Reduction Techniques in Deep-Submicrometer CMOS Circuits. Proceedings of the IEEE, 91, 305-327. https://doi.org/10.1109/JPROC.2002.808156

[26] Calimera, A., MacIi, A., MacIi, E. and Poncino, M. (2012) Design Techniques and 
Architectures for Low-Leakage SRAMs. IEEE Transactions on Circuits and Systems I: Regular Papers, 59, 1992-2007. https://doi.org/10.1109/TCSI.2012.2185303

[27] Tanizawa, M., Ikeda, M., Kotani, N., Tsukamoto, K. and Horie, K. (1993) A Complete Substrate Current Model Including Band-to-Band Tunneling Current for Circuit Simulation. IEEE Transactions on Computer-Aided Design of Integrated Circuits and Systems, 12, 1749-1757. https://doi.org/10.1109/43.248086

[28] Antognetti, P., Caviglia, D.D. and Profumo, E. (1982) CAD Model for Threshold and Subthreshold Conduction in MOSFET's. IEEE Journal of Solid-State Circuits, 17, 454-458. https://doi.org/10.1109/JSSC.1982.1051759

[29] Narendra, S., De, V., Borkar, S., Antoniadis, D. and Chandrakasan, A. (2002) FullChip Sub-Threshold Leakage Power Prediction Model for Sub-0.18 um CMOS. International Symposium on Low Power Electronincs and Design, Monterey, CA, 12-14 August 2002, 19-23. https://doi.org/10.1145/566408.566415

[30] Pavasovic, A., Andreou, A.G. and Westgate, C.R. (1994) Characterization of Subthreshold MOS Mismatch in Transistors for VLSI Systems. Analog Integrated Circuits and Signal Processing, 6, 75-85. https://doi.org/10.1007/BF01250737

[31] Chang, I.J., Park, S.P. and Roy, K. (2010) Exploring Asynchronous Design Techniques for Process-Tolerant and Energy-Efficient Subthreshold Operation. IEEE Journal of Solid-State Circuits, 45, 401-410. https://doi.org/10.1109/JSSC.2009.2036764

[32] Guo, J., Liu, Y., Chou, M.H., Wang, M.T. and Shone, F. (1998) A Three-Terminal Band-Trap-Band Tunneling Model for Drain Engineering and Substrate Bias Effect on GIDL in MOSFET. IEEE Transactions on Electron Devices, 45, 1518-1523. https://doi.org/10.1109/16.701483

[33] Ghodsi, R., Sharifzadeh, S. and Majjiga, J. (1998) Gate-Induced Drain-Leakage in Buried-Channel PMOS: A Limiting Factor in Development. IEEE Electron Device Letters, 19, 354-356. https://doi.org/10.1109/55.709642

[34] Xu, Y., Chi, B. and Wang, Z. (2013) Gate-Leakage Compensation Scheme for Programmable SI-DAC of Modulator in Deep Sub-Micron. Analog Integrated Circuits and Signal Processing, 76, 155-160. https://doi.org/10.1007/s10470-013-0073-3

[35] Rosar, M., Leroy, B. and Schweeger, G. (2000) A New Model for the Description of Gate Voltage and Temperature Dependence of Gate Induced Drain Leakage (GIDL) in the Low Electric Field Region. IEEE Transactions on Electron Devices, 47, 154159. https://doi.org/10.1109/16.817581

[36] Yuan, X., Park, J.E., Wang, J., Zhao, E., Ahlgren, D.C., Hook, T., et al. (2008) GateInduced-Drain-Leakage Current in 45-nm CMOS Technology. IEEE Transactions on Device and Materials Reliability, 8, 501-508. https://doi.org/10.1109/TDMR.2008.2002350

[37] Ana, F. and Najeeb-Ud-Din (2012) Suppression of Gate Induced Drain Leakage Current (GIDL) by Gate Work Function Engineering: Analysis and Model. Journal of Electronic Devices, 13, 984-996.

[38] Gupta, A.D.A.S. and Lahiri, S.K. (1990) An Aanalytical Model of Punchthrough Voltage of Short Channel MOSFETS with Nonuniformly Doped Channels. Solid-State Electronics, 33, 395-400. https://doi.org/10.1016/0038-1101(90)90041-C

[39] Keshavarzi, A., Roy, K., Lafayette, W. and Hawkins, C.F. (1997) Intrinsic Leakage in Low Power Deep Submicron CMOS ICs. International Test Conference, 6 November 1997, 146-155. https://doi.org/10.1109/test.1997.639607

[40] Fu, K.Y. and Tsang, Y.L. (1997) On the Punchthrough Phenomenon in Submicron MOS Transistors. IEEE Transactions on Electron Devices, 44, 847-855. 
https://doi.org/10.1109/16.568048

[41] Fu, K.-Y. and Tsang, Y.L. (1997) Punchthrough Currents in Sub-Micron Short Channel MOS Transistors. Solid-State Electronics, 41, 435-439.

https://doi.org/10.1016/S0038-1101(96)00103-7

[42] Dennard, R., Gaensslen, F., Yu, W.-N., Rideout, L., Bassous, E. and Le Blanc, A. (1974) Design of Ion-Implanted Small MOSFET'S Dimensions with Very Small Physical Dimensions. IEEE Journal of Solid State Circuits, 9, 257-268. https://doi.org/10.1109/JSSC.1974.1050511

[43] Barron, M.B. (1972) Low Level Currents in Insulated Gate Field Effect Transistors. Solid-State Electronics, 15, 293-302. https://doi.org/10.1016/0038-1101(72)90084-6

[44] Srikantaiah, J. and DasGupta, A. (2012) Quantum Mechanical Effects in Bulk MOSFETs from a Compact Modeling Perspective: A Review. IETE Technical Review, 29, 3-28. https://doi.org/10.4103/0256-4602.93119

[45] Chen, M., Huang, H., Hou, C. and Yang, K. (1998) Back-Gate Bias Enhanced Band-to-Band. IEEE Electron Device Letters, 19, 134-136.

https://doi.org/10.1109/55.663538

[46] Yang, N., Henson, W.K., Wortman, J.J. and Member, S. (2000) A Comparative Study of Gate Direct Tunneling and Drain Leakage Currents in N-MOSFET's with Sub-2-nm Gate Oxides. IEEE Transactions on Electron Devices, 47, 1636-1644. https://doi.org/10.1109/16.853042

[47] Majkusiak, B. and Badri, M.H. (2000) Semiconductor Thickness and Back-Gate Voltage Effects on the Gate Tunnel Current in the MOS/SOI System with an Ultrathin Oxide. IEEE Transactions on Electron Devices, 47, 2347-2351. https://doi.org/10.1109/16.887019

[48] Stadele, M., Tuttle, B.R. and Hess, K. (2009) Tunneling through Ultrathin $\mathrm{SiO}_{2}$ Gate Oxides from Microscopic Models. Journal of Applied Physics, 89, 348-363. https://doi.org/10.1063/1.1330764

[49] Larcher, L., Member, S., Paccagnella, A. and Ghidini, G. (2001) Gate Current in U1trathin MOS Capacitors: A New Model of Tunnel Current. IEEE Transactions on Electron Devices, 48, 271-278. https://doi.org/10.1109/16.902726

[50] Yang, K.N., Huang, H.T., Member, S., Chen, M.J., Member, S., Lin, Y.M. and Liang, M.S. (2001) Characterization and Modeling of Edge Direct Tunneling (EDT) Leakage in Ultrathin Gate Oxide MOSFETs. IEEE Transactions on Electron Devices, 48 , 1159-1164. https://doi.org/10.1109/16.925242

[51] Saheb, Z. and El-Masry, E.I. (2015) Modelling of Direct Tunneling Gate Leakage Current of Floating-Gate CMOS Transistor in sub $100 \mathrm{~nm}$ Technologies. Analog Integrated Circuits and Signal Processing, 84, 67-73. https://doi.org/10.1007/s10470-015-0553-8

[52] Bowman, K.A., Member, S., Wang, L., Member, S., Tang, X., Meindl, J.D. and Fellow, L. (2001) A Circuit-Level Perspective of the Optimum Gate Oxide Thickness. IEEE Transactions on Electron Devices, 48, 1800-1810.

https://doi.org/10.1109/16.936710

[53] Choi, C., Member, S., Nam, K., Member, S., Yu, Z. and Member, S. (2001) Impact of Gate Direct Tunneling Current on Circuit Performance: A Simulation Study. IEEE Transactions on Electron Devices, 48, 2823-2829. https://doi.org/10.1109/16.974710

[54] Murakami, Y. and Shingyouji, T. (1994) Separation and Analysis of Diffusion and Generation Components of pn Junction Leakage Current in Various Silicon Wafers. Journal of Applied Physics, 75, 3548-3552. https://doi.org/10.1063/1.356091

[55] Lee, H. and Hwang, J. (1998) Accurate Extraction of Reverse Leakage Current 
Components of Shallow Silicided p/sup +/-n Junction for Quarter- and Sub-Quarter-Micron MOSFET's. IEEE Transactions on Electron Devices, 45, 1848-1850. https://doi.org/10.1109/16.704389

[56] Karuppanan, P., Ghosh, S., Khan, K. and Bikki, P. (2017) A Fully Differential Operational Amplifier with Slew Rate Enhancer and Adaptive Bias for Ultra Low Power. Journal of Low Power Electronics, 13, 67-75.

[57] Enomoto, T., Oka, Y., Shikano, H., Harada, T. and Science, F. (2002) A Self-Controllable-Voltage-Level (SVL) Circuit for Low-Power, High-Speed CMOS Circuits.

[58] Enomoto, T., Oka, Y. and Shikano, H. (2003) A Self-Controllable Voltage Level (SVL) Circuit and Its Low-Power High-Speed CMOS Circuit Applications. IEEE Journal of Solid-State Circuits, 38, 1220-1226.

https://doi.org/10.1109/JSSC.2003.813248

[59] Deshmukh, J. and Khare, K. (2012) Dynamic SVL and Body Bias for Low Leakage Power and High Performance in CMOS Digital Circuits. International Journal of Electronics, 99, 1717-1728. https://doi.org/10.1080/00207217.2012.692634

[60] Narendra, S., Keshavarzi, A., Bloechel, B.A., Borkar, S. and De, V. (2003) Forward Body Bias for Microprocessors in 130-nm Technology Generation and beyond. IEEE Journal of Solid-State Circuits, 38, 696-701. https://doi.org/10.1109/JSSC.2003.810054

[61] Nakagome, Y., Horiguchi, M., Kawahara, T. and Itoh, K. (2003) Review and Future Prospects of Low-Voltage RAM Circuits. IBM Journal of Research and Development, 47, 525-552. https://doi.org/10.1147/rd.475.0525

[62] Tsuguo, K. and Sakurai, T. (1994) Self-Adjusting Threshold-Voltage Scheme (SATS) for Low Voltage High Speed Operation. Custom Integrated Circuit Conference, San Diego, 1-4 May 1994, 271-274.

[63] Kawahara, T., Horiguchi, M., Kawajiri, Y., Kitsukawa, G., Kure, T. and Aoki, M. (1993) Subthreshold Current Reduction for Decoded-Driver by Self-Reverse Biasing. IEEE Journal of Solid-State Circuits, 28, 1136-1144. https://doi.org/10.1109/4.245594

[64] Horiguchi, M., Sakata, T. and Itoh, K. (1993) Switched-Source-Impedance CMOS Circuit for Low Standby Subthreshold Current Giga-Scale LSI's. IEEE Journal of Solid-State Circuits, 28, 1131-1135. https://doi.org/10.1109/4.245593

[65] Bikki, P. and Karuppanan, P. (2017) Analysis of Low Power Feedthrough Logic with Leakage Control Technique. Accepted at the 4th International IEEE Conference (ICPCES-2017), MNNIT-Allahabad.

[66] Keshavarzi, A., Narendra, S., Borkar, S., Hawkind, C., Roy, K. and De, V. (1999) Technology Scaling Behavior of Optimum Reverse Body Bias for Standby Leakage Power Reduction in CMOS IC's. International Symposium on Low Power Electronics and Design, San Diego, 16-17 August 1999, 252-254. https://doi.org/10.1145/313817.313937

[67] Islam, A. and Hasan, M. (2012) Variability Aware Low Leakage Reliable SRAM Cell Design Technique. Microelectronics Reliability, 52, 1247-1252. https://doi.org/10.1016/j.microrel.2012.01.003

[68] Shimazaki, Y., Zlatanovici, R. and Nikoli, B. (2003) A 9uW $50 \mathrm{MHz} 32 \mathrm{~b}$ Adder Using a Self-Adjested Forward Bosy Bias in SOCs. IEEE International ASIC/SOC Conference, Rochester, 25-28 September 2002, 418-419.

[69] Kim, C.H.I., Kim, J.J., Mukhopadhyay, S. and Roy, K. (2005) A Forward Body-Biased Low-Leakage SRAM Cache: Device, Circuit and Architecture Considerations. 
IEEE Transactions on Very Large Scale Integration Systems, 13, 349-357. https://doi.org/10.1109/TVLSI.2004.842903

[70] Kim, C.H., Kim, J.-J., Mukhopadhyay, S. and Roy, K. (2003) A Forward Body-Biased-Low-Leakage SRAM Cache: Device and Architecture Considerations. Proceedings of the International Symposium on Low Power Electronics and Design, Seoul, 25-27 August 2003, 6-9. https://doi.org/10.1145/871506.871511

[71] Keshavarzi, A., Ma, S., Narendra, S., Bloechel, B., Mistry, K., Ghani, T. and De, V. (2001) Effectiveness of Reverse Body Bias for Leakage Control in Scaled Dual Vt CMOS ICs. Proceedings of the International Symposium on Low Power Electronics and Design, California, 6-7 August 2001, 207-212. https://doi.org/10.1145/383082.383135

[72] Kuroda, T. and Sakurai, T. (1996) A 0.9-V, 150-MHz, 10-mW, 4 mm2, 2-D Discrete Cosine Transform Core Processor with Variable Threshold-Voltage (VT) Scheme. IEEE Journal of Solid-State Circuits, 31, 191-201. https://doi.org/10.1109/JSSC.1996.542322

[73] Mizuno, H., Ishibashi, K. and Shimura, T. (1999) An 18-uA Standby Current 1.8-V, 200-MHz Microprocessor with Self-Substrate-Biased Data-Retention Mode. IEEE Journal of Solid-State Circuits, 34, 1492-1500. https://doi.org/10.1109/4.799853

[74] Zhang, L., Wu, C., Mao, L.-F. and Zheng, J. (2012) Integrated SRAM Compiler with Clamping Diode to Reduce Leakage and Dynamic Power in Nano-CMOS Process. Micro \& Nano Letters, 7, 171-173. https://doi.org/10.1049/mnl.2011.0680

[75] Shukla, N.K. and Pattanaik, M. (2011) Design and Analysis of a Novel Low-Power SRAM Bit-Cell Structure at Deep-Sub-Micron CMOS Technology for Mobile Multimedia Applications. International Journal of Advanced Computer Science and Applications, 2, 43-49.

[76] Neema, V., Chouhan, S.S. and Tokekar, S. (2013) Novel Circuit Technique for Reduction of Leakage Current in Series/Parallel PMOS/NMOS Transistor Stack. IETE Journal of Research, 56, 6-10.

[77] Xu, H., Vemuri, R. and Jone, W.-B. (2011) Dynamic Characteristics of Power Gating During Mode Transition. IEEE Transactions on Very Large Scale Integration Systems, 19, 237-249. https://doi.org/10.1109/TVLSI.2009.2033699

[78] Kim, K.K., Kim, Y. and Choi, K. (2011) Hybrid CMOS and CNFET Power Gating in Ultralow Voltage Design. IEEE Transactions on Nanotechnology, 10, 1439-1448. https://doi.org/10.1109/TNANO.2011.2168236

[79] Powell, M., Falsafi, B., Roy, K. and Vijaykumar, T.N. (2000) Gated-Vdd: A Circuit Technique to Reduce Leakage in Deep-Submicron Cache Memories. ISLPED'O0. Proceedings of the 2000 International Symposium on Low Power Electronics and Design, Rapallo, 25-27 July 2000, 90-95. https://doi.org/10.1145/344166.344526

[80] Powell, M., Yang, S.H., Falsafi, B., Roy, K. and Vijaykumar, T.N. (2001) Reducing Leakage in a High-Performance Deep-Submicron Instruction Cache. IEEE Transactions on Very Large Scale Integration Systems, 9, 77-89. https://doi.org/10.1109/92.920821

[81] Ye, Y., Borkar, S. and De, V. (1998) A New Technique for Standby Leakage Reduction in High-Performance Circuits. 1998 Symposium on VLSI Circuits, Honolulu, 11-13 June 1998, 69-70.

[82] Agarwal, A., Li, H. and Roy, K. (2003) A Single-Vt Low-Leakage Gated-Ground Cache for Deep Submicron. IEEE Journal of Solid-State Circuits, 38, 319-328. https://doi.org/10.1109/JSSC.2002.807414

[83] Agarwal, A., Li, H. and Roy, K. (2002) DRG-Cache: A Data Retention Gated- 
Ground Cache for Low Power. Proceedings of the Design Automation Conference, New Orleans, 10-14 June 2002, 473-478. https://doi.org/10.1145/513918.514037

[84] Elakkumanan, P., Narasimhan, A. and Sridhar, R. (2003) NC-SRAM-A Low-Leakage Memory Circuit for Ultra Deep Submicron Designs. Proceedings of IEEE International SOC Conference, Portland, 17-20 September 2003, 3-6. https://doi.org/10.1109/soc.2003.1241450

[85] Goel, A., Sharma, R.K. and Gupta, A. (2014) Area Efficient Diode and on Transistor Inter-Changeable Power Gating Scheme with Trim Options for SRAM Design in Nano-Complementary Metal Oxide Semiconductor Technology. IET Circuits, Devices \& Systems, 8, 100-106. https://doi.org/10.1049/iet-cds.2013.0205

[86] Bhavnagarwala, A.J., Kosonocky, S.V., Immediato, M., Knebel, D. and Haen, A.M. (2003) A Pico-Joule Class, $1 \mathrm{GHz}, 32 \mathrm{kB} 64$ b DSP SRAM with Self Reversed Bias. 2003 Symposium on VLSI Circuits, Kyoto, 12-14 June 2003, 251-252.

[87] Min, I. and Kanda, K. (2003) Row-by-Row Dynamic Source-Line Voltage Control (RRDSV) Scheme for Two orders of Magnitude Leakage SRAM's Current Reduction of Sub-1-V-Vdd. 2003 International Symposium on Low Power Electronics and Design, Seoul, 25-27 August 2003, 66-71.

[88] Devices, M., Yang, H., Member, S., Hwang, W. and Chuang, C. (2011) Impacts of NBTI/PBTI and Contact Resistance on Power-Gated SRAM with High-. IEEE Transactions on Very Large Scale Integration Systems, 19, 1192-1204. https://doi.org/10.1109/TVLSI.2010.2049038

[89] Xie, L., Liu, J. and Wang, Y. (2014) A Low Power CMOS Voltage Reference Generator with Temperature and Process Compensation. Analog Integrated Circuits and Signal Processing, 81, 313-324. https://doi.org/10.1007/s10470-014-0360-7

[90] Zhang, K., Bhattacharya, U., Chen, Z., Hamzaoglu, F., Murray, D., Vallepalli, N. and Bohr, M. (2005) SRAM Design on 65-nm CMOS Technology with Dynamic Sleep Transistor for Leakage Reduction. IEEE Journal of Solid-State Circuits, 40, 895-900. https://doi.org/10.1109/JSSC.2004.842846

[91] Khellah, M., Somasekhar, D., Ye, Y., Kim, N.S., Howard, J., Ruhl, G. and De, V. (2007) A 256-Kb dual-Vcc SRAM Building Block in 65-nm CMOS Process with Actively Clamped Sleep Transistor. IEEE Journal of Solid-State Circuits, 42, 233-241. https://doi.org/10.1109/JSSC.2006.888357

[92] Goel, A., Evans, D., Stephani, R., Reddy, V., Rai, D., Chary, V. and Sathisha, N. (2012) An Area Efficient Diode and on Transistor Interchangeable Power Gating Scheme with Trim Options for Low Power SRAMs. Proceedings of the IEEE International Conference on VLSI Design, Hyderabad, 7-11 January 2012, 80-84. https://doi.org/10.1109/vlsid.2012.50

[93] Itoh, K., Nakagome, Y. and Sasaki, K. (1995) Trends in Low-Power RAM Circuit Technologies. Proceedings of the IEEE, 83, 524-543.

https://doi.org/10.1109/5.371965

[94] Mutoh, S., Douseki, T., Matsuya, Y., Aoki, T., Shigematsu, S. and Yamada, J. (1995) 1-V Power Supply High-Speed Digital Circuit Technology with Multithreshold-Voltage CMOS. IEEE Journal of Solid-State Circuits, 30, 847-854. https://doi.org/10.1109/4.400426

[95] Bikki, P. and Karuppanan, P. (2016) Analysis of Low Power and High Performance Multi-Vth Dual Mode Logic Design. Presented at the 11th International IEEE Conference (ICIIS-2016), IIT-Roorkee.

[96] Bhavnagarwala, A.J., Tang, X. and Meindl, J.D. (2001) The Impact of Intrinsic Device Fluctuations on CMOS SRAM Cell Stability. IEEE Journal of Solid-State Circuits, 36, 658-665. https://doi.org/10.1109/4.913744 
[97] Azizi, N., Member, S., Najm, F.N., Moshovos, A. and Member, A. (2003) LowLeakage Asymmetric-Cell SRAM. IEEE Transactions on Very Large Scale Integration Systems, 11, 701-715. https://doi.org/10.1109/TVLSI.2003.816139

[98] Azizi, N. and Moshovos, A. (2002) Asymmetric-Cell Caches: Exploiting Bit Value Biases to Reduce Leakage Power in Deep-Submicron, High-Performance Caches. TR-01-01-02, ECE Dept., Univ. of Toronto, Toronto, 1-14. http://www.eecg.toronto.edu/ moshovos/research/asram-tr.pdf

[99] Calhoun, B.H. and Chandrakasan, A.P. (2007) A 256-kb 65-nm Sub-Threshold SRAM Design for Ultra-Low-Voltage Operation. IEEE Journal of Solid-State Circuits, 42, 680-688. https://doi.org/10.1109/JSSC.2006.891726

[100] Do, A.T., Nguyen, T.Q., Yeo, K.S. and Kim, T.T. (2013) Sensing Margin Enhancement Techniques for Ultra-Low-Voltage SRAMs Utilizing a Bitline-Boosting Current and Equalized Bitline Leakage. IEEE Transactions on Circuits and Systems II: Express Briefs, 59, 868-872. https://doi.org/10.1109/TCSII.2012.2231014

[101] Chen, S.H., Lin, Y.L. and Chao, M.C.T. (2013) Power-Up Sequence Control for MTCMOS Designs. IEEE Transactions on Very Large Scale Integration Systems, 21, 413-423. https://doi.org/10.1109/TVLSI.2012.2187689

[102] Kim, T.H., Liu, J. and Kim, C.H. (2009) A Voltage Scalable 0.26 V, 64 kb 8T SRAM with Vmin Lowering Techniques and Deep Sleep Mode. IEEE Journal of Solid-State Circuits, 44, 1785-1795. https://doi.org/10.1109/JSSC.2009.2020201

[103] Alvandpour, A., Somasekhar, D., Krishnamurthy, R., De, V., Borkar, S. and Svensson, C. (2003) Bitline Leakage Equalization for Sub-100nm Caches. European SolidState Circuits Conference, Estoril, 16-18 September 2003, 401-404. https://doi.org/10.1109/esscirc.2003.1257157

[104] Wang, B., Nguyen, T.Q., Do, A.T., Zhou, J., Je, M. and Kim, T.T.H. (2015) Design of an Ultra-Low Voltage 9T SRAM with Equalized Bitline Leakage and CAM-Assisted Energy Efficiency Improvement. IEEE Transactions on Circuits and Systems I: Regular Papers, 62, 441-448. https://doi.org/10.1109/TCSI.2014.2360760

[105] Teman, A., Pergament, L., Cohen, O. and Fish, A. (2011) A 250 mV 8 kb 40 nm Ultra-Low Power 9T Supply Feedback SRAM (SF-SRAM). IEEE Journal of Solid-State Circuits, 46, 2713-2726. https://doi.org/10.1109/JSSC.2011.2164009

[106] Mezhibovsky, J., Teman, A. and Fish, A. (2011) Low Voltage SRAMs and the Scalability of the 9T Supply Feedback SRAM. International System on Chip Conference, Taipei, 26-28 September 2011, 136-141.

[107] Kawaguchi, H., Itaka, Y. and Sakurai, T. (1998) Dynamic Leakage Cut-Off Scheme for Low-Voltage SRAM's. 1998 Symposium on VLSI Circuits, Honolulu, 11-13 June 1998, 140-141. https://doi.org/10.1109/vlsic.1998.688035

[108] Kim, C.H. and Roy, K. (2002) Dynamic Vt SRAM: A Leakage Tolerant Cache Memory for Low Voltage Microprocessors. Proceedings of the International Symposium on Low Power Electronics and Design, California, 12-14 August 2002, 251 254. https://doi.org/10.1145/566408.566473

[109] Yamauchi, H., Iwata, T., Akamatsu, H., Matsuzawa, A. and Introduction, I. (1996) A $0.8 \mathrm{~V} / 100 \mathrm{MHz} / \mathrm{sub}-5 \mathrm{~mW}$-Operated Mega-Bit SRAM Cell Architecture with Charge-Recycle Offset-Source Driving (OSD) Scheme. 1996 Symposium on VLSI Circuits, Honolulu, 13-15 June 1996, 126-127.

[110] Osada, K., Saitoh, Y., Ibe, E. and Ishibashi, K. (2003) 16.7fA/Cell Tunnel-Leakage-Suppressed $16 \mathrm{Mb}$ SRAM for Handling Cosmic-Ray-Induced Multi-Errors. IEEE International Solid-State Circuits Conference, San Franciso, 13 February 2003, 168-169. 


\section{Abbreviations}

$\begin{array}{ll}\text { BTBT } & \text { Band-to-band tunneling } \\ \text { BL } & \text { Bit line } \\ \text { BLB } & \text { Bit line bar } \\ \text { CMOS } & \text { Complementary metal oxide semiconductor } \\ \text { DIBL } & \text { Drain-induced barrier lowering } \\ \text { DRG } & \text { Data retention gated-ground } \\ \text { D2D } & \text { Die to die } \\ \text { FBB } & \text { Forward body biasing } \\ \text { GIDL } & \text { Gate-induced drain leakage } \\ I_{\text {BTBT }} & \text { Band to band tunneling effect } \\ I_{g c} & \text { Gate-to-channel current } \\ I_{\text {GIDL }} & \text { Gate-induced drain leakage } \\ I_{\text {Punch }} & \text { Punch-through leakage } \\ I_{\text {Sdif }} & \text { Sub-threshold surface diffusion current } \\ I_{\text {Sub-th }} & \text { Sub-threshold leakage current } \\ \text { Low- } V_{T H} & \text { Low threshold voltage } \\ \text { NBTI } & \text { Negative bias temperature instability } \\ \text { PBTI } & \text { Positive bias temperature instability } \\ \text { PBT } & \text { Programmable bias transistor } \\ \text { PD } & \text { Pull-down } \\ \text { RBB } & \text { Reverse body bias } \\ \text { RBL } & \text { Read word line } \\ \text { SBT } & \text { Self-biasing transistor } \\ \text { SCE } & \text { short-channel effect } \\ \text { SNM } & \text { Signal to noise margin } \\ \text { SRAM } & \text { Static random access memory } \\ \text { SRB } & \text { Self-reverse biasing } \\ \text { VTCMOS } & \text { Variable threshold CMOs } \\ V_{S L} & \text { Virtual source line } \\ & \end{array}$


Submit or recommend next manuscript to SCIRP and we will provide best service for you:

Accepting pre-submission inquiries through Email, Facebook, LinkedIn, Twitter, etc. A wide selection of journals (inclusive of 9 subjects, more than 200 journals)

Providing 24-hour high-quality service

User-friendly online submission system

Fair and swift peer-review system

Efficient typesetting and proofreading procedure

Display of the result of downloads and visits, as well as the number of cited articles Maximum dissemination of your research work

Submit your manuscript at: http://papersubmission.scirp.org/

Or contact cs@scirp.org 